\title{
Transport of the Major Myelin Proteolipid Protein Is Directed by VAMP3 and VAMP7
}

\author{
Anke Feldmann, ${ }^{1 \star}$ Jesa Amphornrat, ${ }^{1 \star}$ Madeleine Schönherr, ${ }^{1}$ Christine Winterstein, ${ }^{1}$ Wiebke Möbius, ${ }^{2}$ \\ Torben Ruhwedel, ${ }^{2}$ Lydia Danglot, ${ }^{3}$ Klaus-Armin Nave, ${ }^{2}$ Thierry Galli, ${ }^{3}$ Dieter Bruns, ${ }^{4}$ Jacqueline Trotter, ${ }^{1}$ \\ and Eva-Maria Krämer-Albers ${ }^{1}$ \\ ${ }^{1}$ Department of Biology, Molecular Cell Biology, University of Mainz, D-55128 Mainz, Germany, ${ }^{2}$ Department of Neurogenetics, Max Planck Institute of \\ Experimental Medicine, D-37075 Göttingen, Germany, 3“Membrane Traffic in Neuronal and Epithelial Morphogenesis," Inserm Equipe de Recherche \\ Labellisée Unité 950, Program in Development and Neurobiology, Institut Jacques Monod, Unité Mixte de Recherche 7592, Centre National de la Recherche \\ Scientifique, University Denis Diderot-Paris 7, F-75013 Paris, France, and ${ }^{4}$ Institute for Physiology, School of Medicine, University of Saarland, D-66421 \\ Homburg, Germany
}

CNS myelination by oligodendrocytes requires directed transport of myelin membrane components and a timely and spatially controlled membrane expansion. In this study, we show the functional involvement of the R-soluble $N$-ethylmaleimide-sensitive factor attachment protein receptor (R-SNARE) proteins VAMP3/cellubrevin and VAMP7/TI-VAMP in myelin membrane trafficking. VAMP3 and VAMP7 colocalize with the major myelin proteolipid protein (PLP) in recycling endosomes and late endosomes/lysosomes, respectively. Interference with VAMP3 or VAMP7 function using small interfering RNA-mediated silencing and exogenous expression of dominantnegative proteins diminished transport of PLP to the oligodendroglial cell surface. In addition, the association of PLP with myelin-like membranes produced by oligodendrocytes cocultured with cortical neurons was reduced. We furthermore identified Syntaxin-4 and Syntaxin-3 as prime acceptor Q-SNAREs of VAMP3 and VAMP7, respectively. Analysis of VAMP3-deficient mice revealed no myelination defects. Interestingly, AP-3 $\delta$-deficient mocha mice, which suffer from impaired secretion of lysosome-related organelles and missorting of VAMP7, exhibit a mild dysmyelination characterized by reduced levels of select myelin proteins, including PLP. We conclude that PLP reaches the cell surface via at least two trafficking pathways with distinct regulations: (1) VAMP3 mediates fusion of recycling endosomederived vesicles with the oligodendroglial plasma membrane in the course of the secretory pathway; (2) VAMP7 controls exocytosis of PLP from late endosomal/lysosomal organelles as part of a transcytosis pathway. Our in vivo data suggest that exocytosis of lysosomerelated organelles controlled by VAMP7 contributes to myelin biogenesis by delivering cargo to the myelin membrane.

\section{Introduction}

CNS myelin is produced during postnatal development as a specialized subdomain of the oligodendrocyte plasma membrane that wraps and compacts around axons in response to selective axon-glia interaction (Sherman and Brophy, 2005; Simons and Trajkovic, 2006; Simons and Trotter, 2007). The cellular mechanisms of myelin formation are not well understood, but indeed essential to fully grasp pathology of myelin disease and to tackle the problem of inefficient remyelination associated with most

Received Dec. 20, 2010; revised Jan. 28, 2011; accepted Feb. 7, 2011.

This study was supported by grants from the European Union SP6 "Signalling and Traffic" (J.T.), the European Leukodystrophy Association, and "Inneruniversitäre Forschungsförderung Stufe 1" University of Mainz (E.-M.K.-A.). We thank Ulrike Stapf and Lilja Niedens for excellent technical assistance. We thank T. Weimbs (Santa Barbara, CA) and T. Binz (Hannover, Germany) for the kind gift of reagents. Reinhard Windoffer (Aachen, Germany) kindly helped with image analysis.

*A.F. and J.A. contributed equally to this work.

Correspondence should be addressed to Eva-Maria Krämer-Albers, Department of Molecular Cell Biology, Johannes Gutenberg University of Mainz, Bentzelweg 3, D-55128 Mainz, Germany. E-mail: emkraemer@ uni-mainz.de.

C. Winterstein's present address: Department of Molecular, Cellular, and Developmental Biology, University of California, Santa Barbara, CA 93106.

DOI:10.1523/JNEUROSCI.6638-10.2011

Copyright $\odot 2011$ the authors $\quad 0270-6474 / 11 / 315659-14 \$ 15.00 / 0$ diseases including multiple sclerosis. A major challenge for oligodendrocytes, which ensheath multiple axon segments simultaneously, is the temporal and spatial orchestration of myelin membrane synthesis and traffic to control membrane domain morphogenesis and the directed growth of the emerging myelin sheath (Krämer et al., 2001; Baron and Hoekstra, 2010). Several myelin proteins undergo distinct endocytic sorting and recycling associated with plasma membrane remodeling (Winterstein et al., 2008). Intriguingly, assembly of the two major myelin proteins with the myelin membrane is regulated by neuronal signals: axon-glia contact induces the localized translation of myelin basic protein (MBP) (White et al., 2008), and moreover, soluble neuronal signals trigger exocytosis of the proteolipid protein (PLP) from late endosomal membrane stores (Trajkovic et al., 2006).

How myelinating cells achieve the specific targeting and fusion of vesicles transporting myelin components required for the expansion of the myelin membrane is unknown. In all eukaryotic cells, the specificity of vesicle fusion is mediated by complementary action of Sec1/Munc18-like, soluble $N$-ethylmaleimidesensitive factor attachment protein receptor (SNARE) proteins and their regulators (Jahn and Scheller, 2006; Südhof and Roth- 
man, 2009). SNAREs represent a familiy of 36 proteins in humans and are the core components of the membrane fusion machinery. Vesicular and target membrane-localized SNAREs interact to form an intertwined $\alpha$-helical bundle consisting of four coiledcoil domains (SNARE motifs) pulling the opposing membranes together and exerting the force required for fusion (Li et al., 2007). SNAREs have been classified according to structural criteria of their SNARE motifs. Execution of fusion requires the assembly of each one R-SNARE (contributed by the vesicular SNARE), $Q_{a}, Q_{b}$, and $Q_{c}$ SNARE (contributed by target membrane SNAREs) within the four-helix bundle (Fasshauer et al., 1998; Bock et al., 2001). Distinct combinations of R- and Q-SNAREs mediate individual fusion reactions ( $\mathrm{McNew}$ et al., 2000; Scales et al., 2000); hence the localization of SNARE proteins is determined by their involvement in specific trafficking pathways.

To identify SNAREs mediating fusion in myelin membrane traffic, we initially performed a systematic analysis of oligodendroglial SNARE expression, localization, and putative complex formation facilitating the choice of individual SNAREs for functional analyses (Feldmann et al., 2009). Here, we explore the functional involvement of the R-SNAREs VAMP3 [cellubrevin (McMahon et al., 1993)] and VAMP7 [tetanus neurotoxininsensitive (TI)-VAMP (Galli et al., 1998)] in myelin membrane trafficking in vitro and in vivo focusing on transport of the major myelin protein PLP. The results reveal that both R-SNAREs mediate surface transport of PLP involving a VAMP3-dependent pathway from recycling endosomes (REs) to the plasma membrane and a VAMP7-dependent pathway controlling exocytosis of lysosome-related organelles [late endosomes/lysosomes (LE/ Lys)] delivering cargo to the myelin sheath.

\section{Materials and Methods}

Antibodies and expression vectors. Antibodies used were as follows: mouse anti-cyclic nucleotide phosphodiesterase (CNP), clone 11-B5; mouse anti-c-myc, clone 9E10; rabbit anti-myc (Cell Signaling Technology); mouse anti- $\beta$-tubulin isotype III, clone SDL 3D10 (Sigma-Aldrich); rat anti-MBP, clone 12 (Serotec); rabbit anti-enhanced green fluorescent protein (EGFP), Living Colors Full-Length A.v. (Clontech); rat antiLAMP1, CD107a, clone 1D4B (BD Biosciences Transduction Laboratories); mouse anti-human transferrin receptor, clone H68.4 (Zymed Laboratories); rabbit anti-VAMP3/cellubrevin, rabbit anti-Syntaxin-2 (Stx2), rabbit anti-Syntaxin-3, and rabbit anti-Syntaxin-4 (all Synaptic Systems); mouse anti-myelin oligodendrocyte glycoprotein (MOG), clone 8-18-C5 (C. Linington, University of Glasgow, Glasgow, UK); rat anti-PLP, clone aa3 recognizing the C-terminal region of PLP (Dr. M. B. Lees, E.K. Shriver Center, Waltham, MA); mouse anti-PLP, clone O10 recognizing a cell surface epitope of PLP (Jung et al., 1996); rabbit antiPLP, clone P6 (C. Linington); rat anti-L1, clone 324 (M. Schachner, Zentrum für Molekulare Neurobiologie, Hamburg, Germany); mouse anti-VAMP2 antibody, clone 69.1 (R. Jahn, Max Planck Institute for Biophysical Chemistry, Göttingen, Germany); mouse anti-VAMP7 antibody (TI-VAMP), clone 158.2 (T. Galli, INSERM U950, Institut Jacques Monod, Paris, France; Covalab) (Martinez-Arca et al., 2000). Secondary antibodies were purchased from Dianova, except anti-mouse IRDye 800 (LI-COR) and anti-rat Alexa Fluor 680 (Invitrogen) used in the multiplex in cell assay.

Expression vectors used were as follows: pCMV-PLP (Krämer-Albers et al., 2006); pEYFP-N1-MOG has been subcloned from pcDNA3.1-MOG using BglII and HindIII restriction sites; pEGFP-C3-TI-VAMP, pEGFP-C3Nter-TI-VAMP, and pEGFP-C3-cellubrevin (Martinez-Arca et al., 2000, 2003); pCMV5-TeNT and pCMV5-TeNT-E234Q (McMahon et al., 1993) kindly provided by T. Binz (Institute for Physiological Chemistry, Medizinische Hochschule Hannover, Hannover, Germany); pcDNA4/TO/ myc-HisA-Syntaxin-2, pcDNA4/TO/myc-HisA-Syntaxin-3, and pcDNA4/
TO/myc-HisA-Syntaxin-4 (Low et al., 2006), kindly provided by T. Weimbs (University of California, Santa Barbara, Santa Barbara, CA).

Animals. Experiments were in compliance with the animal policies of the University of Mainz, approved by the German Federal State of Rheinland Pfalz, in accordance with the European Community Council Directive of November 24, 1986 (86_609_EEC). For preparation of primary oligodendrocyte cultures, mice of either sex of the strains NMRI or C57BL6-N were used. AP-3 $\delta$-deficient mocha mice (Kantheti et al., 1998; Danglot and Galli, 2007) and wild-type littermates of either sex were provided by T. Galli. VAMP3-deficient mice (Yang et al., 2001; Borisovska et al., 2005) and wild-type littermates of either sex were provided by D. Bruns (Institute for Physiology, School of Medicine, University of Saarland, Homburg/Saar, Germany).

Cell culture, transfection, and RNAi. Primary cultures of mouse oligodendrocytes were prepared as described previously (Krämer et al., 1997). The cell lines Oli-neu (Jung et al., 1995) or Oli-neu stably expressing PLP-EGFP (Oli-neu PLP-EGFP) (Trajkovic et al., 2006) were cultured in Sato medium containing $1 \%$ horse serum and were treated with $1 \mathrm{~mm}$ dibutyryl-cAMP (dbcAMP) (Sigma-Aldrich) if applicable.

Oli-neu cells were transfected by electroporation using a GenePulser Xcell (Bio-Rad) as described previously (Krämer-Albers et al., 2006). Small interfering RNA (siRNA) transfection of primary oligodendrocytes (performed immediately after shake-off from astrocyte monolayer) and Oli-neu cells was performed using Amaxa Biosystems technology according to the manufacturer's instructions (AmaxaNucleofector kit, Primary Neurons; program O-005). Synthetic siRNAs against VAMP3 (target sequence: $5^{\prime}$-AAG ATT ATT CTC CGT TTG TAA-3'), VAMP7 (target sequence: $5^{\prime}$-CTC CTT GTA AAT GAT ACA CAA-3') and nonsilencing control-siRNA (target sequence: $5^{\prime}$-AAT TCT CCG AAC GTG TCA CGT-3') were obtained from QIAGEN.

Cocultures of neurons and oligodendrocytes were obtained by seeding purified primary oligodendrocytes onto primary cortical neurons. Cortical neurons were prepared according to a modified protocol by Hoogenraad et al. (2010). Cortices of embryonic day 15 mice were dissociated in $1 \%$ trypsin $/ 0.05 \%$ DNase in HBSS using a fire-polished Pasteur pipette to obtain a single-cell suspension followed by seeding on poly-L-lysine-coated dishes in plating medium containing Neurobasal (Invitrogen), B27 supplement (Invitrogen), L-glutamine (0.5 mM; Invitrogen), glutamate (12.5 $\mu \mathrm{M}$; Sigma-Aldrich), and penicillin/streptomycin (Serva). The next day, medium was exchanged to feeding medium containing Neurobasal (Invitrogen), B27 supplement (Invitrogen), L-glutamine $(0.5 \mathrm{~mm})$, and penicillin/streptomycin (Serva). These conditions favor survival selectively of neurons. One-half of the medium was renewed every 3-4 d. After $7 \mathrm{~d}$, siRNA-transfected primary oligodendrocytes were seeded on top of the neurons and cocultures were grown in Sato medium including B27, 1\% horse serum, PDGF (10 $\mathrm{ng} / \mathrm{ml}$; PeproTech), and FGF (5 ng/ml; PeproTech). Fractionation of myelin-like membranes was performed after $5 \mathrm{~d}$ of neuron-oligodendrocyte coculture.

Immunocytochemistry, imaging, and quantitative analysis. Primary oligodendrocytes or Oli-neu cells were fixed in $4 \%$ paraformaldehyde in PBS and permeabilized for 2 min with $0.1 \%$ Triton X-100 in PBS. After blocking with $10 \%$ horse serum in PBS (20 min), cells were incubated for 45 min with primary antibodies followed by dye-conjugated secondary antibodies (30 $\mathrm{min})$ and were finally mounted. Stainings involving the O10 antibody, recognizing a cell surface epitope of PLP, were performed on live cells before fixation. Confocal images were acquired with a Leica TCS SP5 laser-scanning microscope using a $63 \times, 1.4$ numerical aperture lens and LAS AF software (Leica).

To determine the relative surface localization of PLP, PLP surface epitopes and total PLP epitopes were quantified from confocal $z$-stacks. Single cells were scanned in 20 sections (every $0.4 \mu \mathrm{m}$ ) along the $z$-axis ( 8 $\mu \mathrm{m})$ using standardized microscope settings for each channel. Total fluorescence intensity in each channel was evaluated by summing up the grayscale values of the pixels that were above background. Relative surface localization was expressed as ratio of the intensities calculated from surface PLP (O10 stain) and total PLP (aa3 stain or PLP-EGFP fluorescence). Control values were set to $100 \%$, and experimental values were expressed in relation. At least $15-20$ cells were evaluated and averaged per 
experiment. Statistical analysis was performed on three independent experiments using GraphPad Prism 5.00 software (two-tailed Student's $t$ test). Images presented in figures were processed with Adobe Photoshop using linear adjustment of histograms.

Brain homogenates and myelin isolation. Brains of postnatal day 30 (P30) mice (of either sex) were removed from the skull, and wet weight was determined. Subsequently, brains were homogenized in ice-cold 0.3 M sucrose in PBS using an Ultra Turrax (IKA-Gruppe). Myelin was isolated from brain homogenates using a modified method of discontinuous sucrose density gradient centrifugation (Norton and Poduslo, 1973; Krämer et al., 1997). Briefly, homogenates were centrifuged for $45 \mathrm{~min}$ at $17,000 \times g$. The pellet was resuspended in $0.8 \mathrm{~m}$ sucrose, overlaid with 0.3 M sucrose, and centrifuged for $50 \mathrm{~min}$ at $68,000 \times g$. Myelin was collected from the interface and subjected to two rounds of hypo-osmotic shock by resuspension in a large volume of ice-cold water followed by pelleting to loosen myelin membranes from the axolemma. After a final density gradient centrifugation, myelin was collected from the $0.3 / 0.8 \mathrm{M}$ interface, washed with cold water, pelleted for $30 \mathrm{~min}$ at $68,000 \times \mathrm{g}$, and resuspended in a small volume of PBS. The protein concentration of total brain homogenates and myelin was determined by Bradford assay.

Fractionation of myelin-like membranes from neuron-glial cultures. Primary oligodendrocytes were transfected with siRNA before seeding onto neurons. After $5 \mathrm{~d}$ of coculture, myelin-like membranes were subfractionated as described by Winterstein et al. (2008) according to a modified protocol (Matthieu et al., 1973; Rios et al., 2000). Cells were scraped in 10 mM Tris, $5 \mathrm{~mm}$ EDTA, $1 \mathrm{~mm}$ PMSF, $1 \mu \mathrm{g} / \mathrm{ml}$ aprotinin, $1 \mu \mathrm{g} / \mathrm{ml}$ pepstatin, and $1 \mu \mathrm{g} / \mathrm{ml}$ leupeptin, $\mathrm{pH} 7.3$, and homogenized by repeated shearing through a 22 ga syringe. Nuclei were pelleted at $300 \times g$ for $10 \mathrm{~min}$, and the resulting postnuclear supernatant was subjected to centrifugation for $10 \mathrm{~min}$ at $20,000 \times \mathrm{g}$ at $4^{\circ} \mathrm{C}$. The pellet was homogenized in $200 \mu \mathrm{l}$ of 0.32 $\mathrm{m}$ sucrose. The $0.32 \mathrm{~m}$ homogenate was loaded on a $0.62 / 0.8 \mathrm{M}$ discontinuous sucrose gradient and centrifuged for $30 \mathrm{~min}$ at $75,000 \times g$ and $4^{\circ} \mathrm{C}$. Three fractions were collected as follows: the $0.32 / 0.62 \mathrm{M}$ interface (light fraction containing myelin-like membranes), the $0.62 / 0.8 \mathrm{M}$ interphase (medium fraction), and the pellet (heavy fraction). The membranes were pelleted from the fractions by centrifugation for $1 \mathrm{~h}$ at $100,000 \times g$ and $4^{\circ} \mathrm{C}$, resuspended in an equal volume of $10 \mathrm{~mm}$ Tris, $\mathrm{pH}$ 7.5, $150 \mathrm{~mm}$ $\mathrm{NaCl}, 1 \% \mathrm{NP}-40,0.5 \%$ sodium deoxycholate, $0.1 \%$ SDS, 2 mм EDTA, 1 mM PMSF, $1 \mu \mathrm{g} / \mathrm{ml}$ aprotinin, $1 \mu \mathrm{g} / \mathrm{ml}$ pepstatin, and $1 \mu \mathrm{g} / \mathrm{ml} \mathrm{leupeptin}$, and analyzed by SDS-PAGE and Western blotting. To calculate the relative amount of myelin-like light membranes in the cultures, Western blots of PLP were subjected to densitometric quantification, and the values of light fractions expressed in relation to the sum of medium and heavy fractions.

SDS-PAGE and Western blotting. SDS-PAGE analysis was performed using self-made $14 \%$ gels, or 4-12\% NuPAGE gels (Invitrogen), according to the manufacturer's instructions. Proteins were blotted onto a PVDF (polyvinylidene difluoride) membrane, which was blocked with $4 \%$ milk powder/ $0.1 \%$ Tween in PBS. Proteins were detected by sequential incubation of the membrane with primary antibodies for $1 \mathrm{~h}$ at room temperature and secondary anti-species antibodies conjugated to horseradish peroxidase (HRP) for $45 \mathrm{~min}$ at room temperature. The blots were developed with enhanced chemiluminescence reagents (Pierce) according to the manufacturer's instructions. Densitometric quantification and statistical analysis (two-tailed Student's $t$ test) of blots was performed with AIDA Image Analyzer, version 3.28, and GraphPad Prism 5 software, respectively.

Cell ELISA. Oli-neu or Oli-neu PLP-EGFP cells $\left(3800 \mathrm{cells} / \mathrm{cm}^{2}\right)$ were grown in the presence or absence of $1 \mathrm{~mm}$ dbcAMP. Cells were incubated with the anti-PLP antibody (clone O10) for $40 \mathrm{~min}$, washed, and fixed with $4 \%$ paraformaldehyde in PBS. After blocking (30 min with PBS and $10 \%$ horse serum), HRP-coupled anti-mouse antibody was incubated for $60 \mathrm{~min}$ and wells were washed three times with PBS. HRPcoupled antibodies were detected using tetramethylbenzidine as substrate (Thermo Fisher Scientific) according to standard procedures. Color development was measured in an ELISA reader (Biotrak II; GE Healthcare) and background values obtained from cells only incubated with HRP antibodies were subtracted. Per experiment, six replicates were averaged and at least three independent experiments were performed before statistical analysis using GraphPad Prism 5.00 software.
Multiplex in-cell assay. siRNA-transfected oligodendrocytes were grown in six-well plates $\left(4 \times 10^{6}\right.$ cells/well $)$ and differentiated for 3-4 d. To detect surface levels of PLP, cells were incubated with O10 antibodies for $45 \mathrm{~min}$, washed, and fixed for $30 \mathrm{~min}$ as described. After permeabilization for $2 \mathrm{~min}$ in PBS, $0.1 \%$ TX-100, and blocking (30 min with PBS and $10 \%$ horse serum), the wells were incubated for $45 \mathrm{~min}$ with aa3 antibodies recognizing total PLP. After washing with $0.1 \%$ Tween 20 in PBS, secondary antibodies (anti-mouse IRDye 800 recognizing $\mathrm{O} 10$ and anti-rat Alexa Fluor 680 recognizing aa3) were diluted in $0.2 \%$ Tween 20 in PBS and incubated for $1 \mathrm{~h}$. Cells were washed with $0.1 \%$ Tween in PBS. All steps were performed at room temperature. Epifluorescence was scanned using the Odyssey Imager (LI-COR). Background values obtained from cells only incubated with secondary antibodies were subtracted, and relative surface levels of PLP were determined by normalizing epifluorescence of surface PLP to that of total PLP. Statistical analysis was performed by application of two-tailed Student's $t$ test using Excel software.

Immunoprecipitation. Oli-neu cells were cotransfected with pEGFPC3-cellubrevin or pEGFP-C3-TI-VAMP and either pcDNA/TO/mycHisA-Stx2, -Stx3, or -Stx4 expression vectors, and immunoprecipitation (IP) was performed $24 \mathrm{~h}$ later as described previously (Feldmann et al., 2009). Briefly, cells were pretreated for $15 \mathrm{~min}$ with $1 \mathrm{~mm}$ $N$-ethylmaleimide in PBS and scraped in $1 \mathrm{ml}$ of lysis buffer (1\% Triton $\mathrm{X}-100,50 \mathrm{~mm}$ Tris, $\mathrm{pH} 7.4,150 \mathrm{~mm} \mathrm{NaCl}, 1 \mu \mathrm{g} / \mathrm{ml}$ aprotinin, $5 \mu \mathrm{g} / \mathrm{ml}$ leupeptin, $1 \mu \mathrm{g} / \mathrm{ml}$ pepstatin, $1 \mathrm{~mm}$ PMSF, and $1 \mathrm{~mm} N$-ethylmaleimide). After nuclei had been removed $(10 \mathrm{~min} ; 300 \times g)$ and lysates were cleared from proteins binding nonspecifically to protein $\mathrm{A}$, lysates were incubated overnight at $4^{\circ} \mathrm{C}$ with polyclonal c-myc antibodies followed by protein A-Sepharose for $1 \mathrm{~h}$ at $4^{\circ} \mathrm{C}$ to precipitate ectopically expressed syntaxins. The pelleted beads were washed five times in $50 \mathrm{~mm}$ Tris- $\mathrm{HCl}$, pH 7.2, $150 \mathrm{~mm} \mathrm{NaCl}, 1 \%$ Triton X-100, 1\% deoxycholate, $0.1 \%$ SDS, 1 mм DTT (1,4-dithiothreitol), $1 \mathrm{~mm} N$-ethylmaleimide, $1 \mu \mathrm{g} / \mathrm{ml}$ aprotinin, $5 \mu \mathrm{g} / \mathrm{ml}$ leupeptin, $1 \mu \mathrm{g} / \mathrm{ml}$ pepstatin, and $1 \mathrm{~mm}$ PMSF. Finally, the beads were resuspended in SDS-PAGE sample buffer and heated for 10 min to $95^{\circ} \mathrm{C}$, and the supernatant was analyzed by SDS-PAGE and Western blotting using either monoclonal myc antibodies to verify syntaxin precipitation or GFP antibodies to detect associated VAMP3 or VAMP7. Total lysates $(\sim 3 \%$ of the lysates before IP) were analyzed as positive control.

Endocytosis assay. Endocytosis of PLP from the cell surface was assessed by antibody internalization as described previously (Winterstein et al., 2008). Oli-neu cells were incubated on ice for $45 \mathrm{~min}$ with $\mathrm{O} 10$ antibodies in DMEM, 10\% horse serum, followed by incubation with goat anti-species $\mathrm{Cy} 3$ antibodies for $30 \mathrm{~min}$ on ice. The cells were either left on ice (control) or incubated at $37^{\circ} \mathrm{C}$ to allow endocytosis and subsequently incubated with anti-goat Cy2 to stain cell surface-localized proteins. Finally, cells were fixed in $4 \%$ paraformaldehyde in PBS. Endocytosed epitopes thus appear solely in the red channel, whereas surfacelocalizing epitopes appear in both red and green channels. The percentage of endocytosing cells was determined from three independent experiments ( 100 cells counted per experiment).

Histochemical staining. For histological analysis, mouse brains were immersion-fixed in $4 \%$ paraformaldehyde in PBS for $3 \mathrm{~h}$ at $4^{\circ} \mathrm{C}$ and sectioned in PBS using a vibratome (Leica VT 1000s; Leica) at $30 \mu \mathrm{m}$. Myelin was visualized by Gallyas silver impregnation (Gallyas, 1979). For immunostainings, sections were permeabilized for $1 \mathrm{~h}$ in $0.4 \%$ Triton $\mathrm{X}-100$ in PBS, blocked for $1 \mathrm{~h}$ in PBS, $10 \%$ normal goat serum (NGS), $0.1 \%$ Triton $\mathrm{X}-100$, and incubated overnight $\left(4^{\circ} \mathrm{C}\right)$ with primary antibodies diluted in PBS, $1 \%$ NGS, $0.1 \%$ Triton X-100. Sections were washed in PBS and incubated with species-specific secondary antibodies coupled to $\mathrm{Cy} 2$ or $\mathrm{Cy} 3$ for $2 \mathrm{~h}$ at room temperature in $1 \%$ NGS in PBS/0.1\% Triton X-100 and mounted on poly-L-lysine-coated slides in Mowiol (Calbiochem). Specimens were analyzed with a Leica DML microscope. Images were processed with Adobe Photoshop software.

Immunoelectron microscopy. Immunoelectron microscopy of cryosections was performed as described previously (Werner et al., 2007). Shortly, 6-d-old mice were fixed by transcardial perfusion with $4 \%$ formaldehyde (Serva) and $0.2 \%$ glutaraldehyde (Science Services) in $0.1 \mathrm{M}$ phosphate buffer containing $0.5 \% \mathrm{NaCl}$. Slices of spinal cord were infil- 
trated in $2.3 \mathrm{M}$ sucrose in $0.1 \mathrm{M}$ phosphate buffer overnight; pieces from the area of the dorsal column were mounted onto aluminum pins for ultramicrotomy and frozen in liquid nitrogen. Primary oligodendrocytes were fixed in $4 \%$ formaldehyde and $0.2 \%$ glutaraldehyde in $0.1 \mathrm{~m}$ phosphate buffer. After washing, the cells were scraped from the dish in $0.1 \mathrm{~m}$ phosphate buffer containing $1 \%$ gelatin, spun down, and resuspended in $10 \%$ gelatin in $0.1 \mathrm{M}$ phosphate buffer at $37^{\circ} \mathrm{C}$. After spinning down, the pellets in gelatin were cooled on ice, removed from the tubes, and cut in small blocks. These blocks were infiltrated in $2.3 \mathrm{M}$ sucrose in $0.1 \mathrm{M}$ phosphate buffer, mounted onto aluminum pins for ultramicrotomy, and frozen in liquid nitrogen. Ultrathin cryosections were prepared using a cryo-ultramicrotome (UC6 equipped with a FC6 cryobox; Leica), picked up in a $1: 1$ mixture of $2 \%$ methylcellulose (SigmaAldrich) and 2.3 m sucrose (Liou et al., 1996). Sections of cell pellets in gelatin were incubated for $20 \mathrm{~min}$ in $\mathrm{PBS}$ at $40^{\circ} \mathrm{C}$ to remove the gelatin before the labeling. For immunolabeling, sections were incubated with rabbit antibodies specific for VAMP3/cellubrevin followed by protein A-gold $(10 \mathrm{~nm})$ or with a monoclonal antibody specific for transferrin receptor detected with rabbit anti-mouse IgG bridging antibody (Rockland) followed by protein A-gold $(10 \mathrm{~nm})$. In a sequential double-labeling procedure, PLP was detected with a polyclonal rabbit antibody (A431) followed by protein A-gold $(15 \mathrm{~nm})$. Protein A coupled to 10 or 15 nm colloidal gold was obtained from the Cell Microscopy Center, Department of Cell Biology, University Medical Center (Utrecht, The Netherlands), and prepared according to Slot and Geuze (1985) and Roth et al. (1978). Sections were analyzed with a LEO EM912 Omega (Zeiss), and digital micrographs were obtained with an on-axis $2048 \times 2048$ CCD camera (Proscan).

Electron microscopy for $\mathrm{g}$ ratio analysis. Heterozygous and AP- $3 \delta$-deficient mocha littermate mice $(n=3)$ were fixed by transcardial perfusion with $4 \%$ formaldehyde and $2.5 \%$ glutaraldehyde in phosphate buffer containing $0.5 \% \mathrm{NaCl}$ according to Karlsson and Schultz (1965) and embedded in Epon (glycid ether). From every animal, five overview pictures from sagittal sections of rostral corpus callosum were taken at $3150 \times$ magnification and $\sim 200$ axons randomly chosen and analyzed using ImageJ (http://rsb.info.nih.gov/ij/). $g$ ratios (axonal diameter divided by the fiber diameter including the myelin sheath) were calculated from circular areas equivalent to the measured areas of axons and myelin sheath including the axon.

\section{Results}

We previously analyzed the SNARE expression profile in oligodendroglial cells, which appeared identical in the cell line Oli-neu and primary oligodendrocytes (Feldmann et al., 2009). VAMP3 localized to the RE and its mRNA expression and protein levels were upregulated during differentiation (Fig. 1). VAMP7 localized to LE/Lys and contrary to other R-SNAREs exhibited a relative enrichment in the myelin membrane during myelination. We thus focused our analyses on these two R-SNAREs.

A
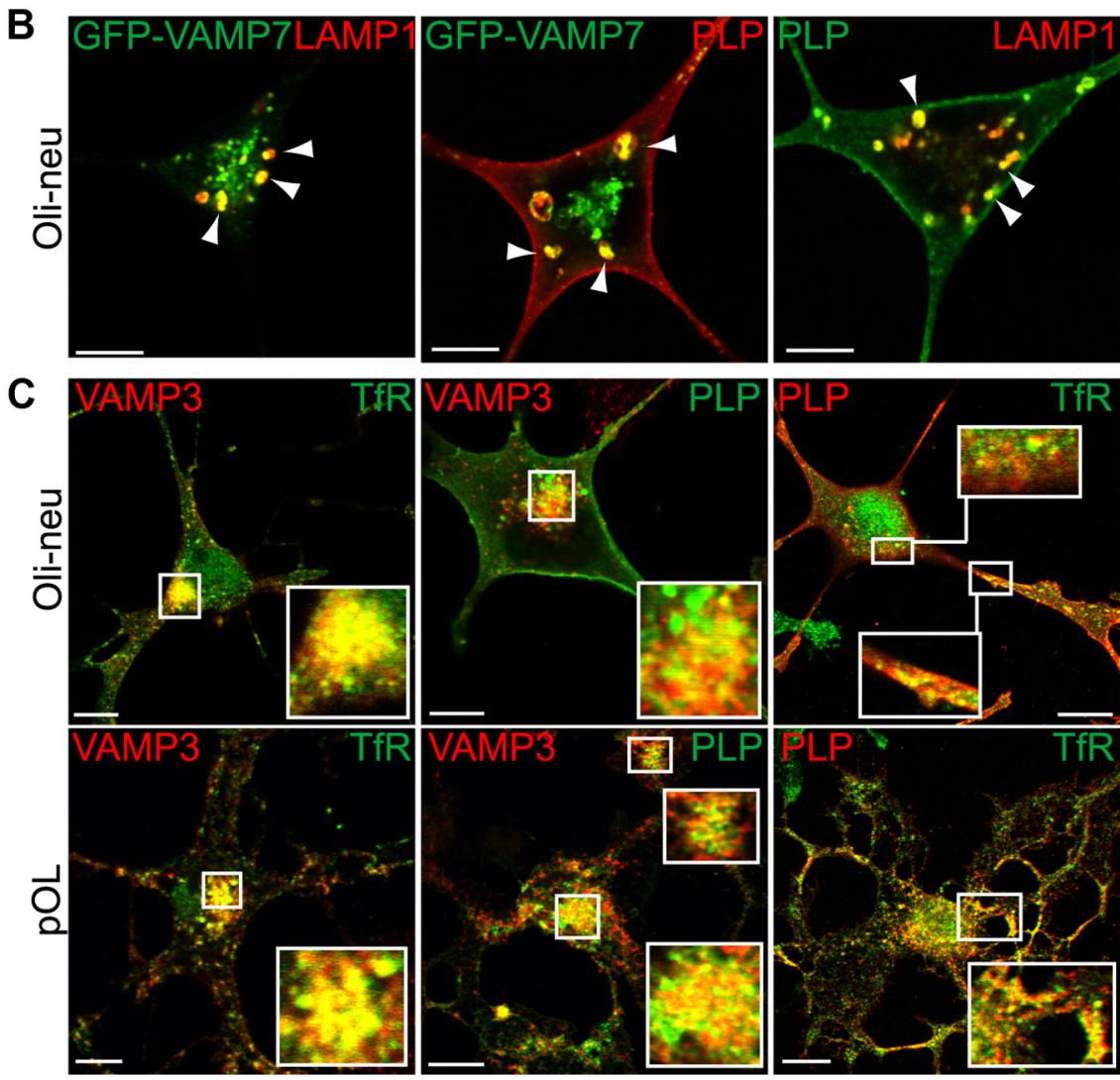

Figure 1. Colocalization of VAMP3 and VAMP7 with PLP in endosomal membranes of oligodendroglial cells. $A$, Western blot analysis of endogenous VAMP3 and VAMP7 protein expression in oligodendroglial cells and myelin isolated from P60 mouse brain. Primary oligodendrocytes (pOL) were analyzed in progenitor (pro) and differentiated (diff) state, cultured for 2 and $8 \mathrm{~d}$, respecNote that VAMP7 antibodies failed to detect VAMP7 by immunocytochemical means. C, Coimmunostaining of VAMP3, PLP, and TfR reveals colocalization of PLP with VAMP3 in recycling endosomes of Oli-neu cells or primary oligodendrocytes. Confocal planes are shown; insets show enlarged areas. Scale bars, $5 \mu \mathrm{m}$.

\section{VAMP3 and VAMP7 colocalize with the major myelin protein PLP}

Vesicular R-SNAREs reside in the membrane of donor compartments together with cargo membrane proteins. To examine whether VAMP3 and VAMP7 containing donor membranes might deliver myelin components, we determined their colocalization with PLP, the most prominent membrane protein of the compact myelin sheath. The antibodies used do not discriminate between PLP and its isoform DM20, which lacks a 35 aa intracellular sequence. Thus, the analysis of primary tissue always comprises both isoforms (as we have no evidence that the isoforms behave differently with regard to trafficking, the acronym PLP is used throughout the study). Inside cells, PLP is localizing to LE/ Lys (Krämer et al., 2001; Trajkovic et al., 2006), and thus we anticipated its colocalization with VAMP7 in this compartment. However, although VAMP7 antibodies clearly recognized endog- 
enously expressed VAMP7 in Western blots (Fig. $1 A$ ), they failed to convincingly label the protein in immunostainings. We thus coexpressed a GFP-VAMP7 fusion protein (Martinez-Arca et al., 2000) and PLP in Oli-neu cells, costained the cells with the LE/Lys marker LAMP1, and imaged cells exhibiting moderate expression levels. Both, GFP-VAMP7 and PLP localize to LAMP1-positive LE/Lys and exhibit a prominent colocalization (Fig. $1 B$ ). In addition, PLP costained with VAMP3, which localizes to RE, in the perinuclear region and peripheral compartments of Oli-neu cells and primary oligodendrocytes (Fig. $1 C$ ). Indeed, colocalization with the transferrin receptor ( $\mathrm{TfR}$ ) confirmed the RE localization of PLP, which however was less pronounced in the steady state compared with its LE/Lys localization. PLP/TfR colocalization was most evident in immature oligodendrocytes exhibiting lower expression levels of PLP, whereas PLP/LAMP1 colocalization appeared rather characteristic for mature cells expressing high levels of PLP, indicating that LE/Lys trafficking of PLP may occur subsequent to RE localization.

Although localization of PLP in LE/Lys as a result of endocytosis from the plasma membrane is well described, RE localization has not been observed before and does not emerge on PLP endocytosis (Winterstein et al., 2008). To further confirm localization of PLP and VAMP3 in the RE on the ultrastructural level, we performed immunoelectron microscopy on primary cultured oligodendrocytes and P6 mouse spinal cord (Fig. 2). Gold particles marking PLP (large $15 \mathrm{~nm}$ particles) and VAMP3 (small 10 $\mathrm{nm}$ particles) coexisted in tubular membranes that appeared in the proximity of the Golgi apparatus of cultured cells (Fig. 2A) and in the cytoplasm of myelinating cells in the spinal cord, frequently within the periaxonal loop (Fig. 2 B). Membranes of similar appearance contained both PLP and the RE marker TfR (Fig. $2 C)$. These membranes are reminiscent of tubular transport intermediates generated from RE to ship cargo to the plasma membrane (D'Souza-Schorey et al., 1998; Maxfield and McGraw, 2004). Unfortunately, coimmunolabelings of VAMP7 appeared on all types of cellular membranes and thus were considered not sufficiently specific to be evaluated. In summary, we conclude that PLP coexists with VAMP3 in RE and with VAMP7 in LE.

\section{Functional inactivation of VAMP3 reduces PLP surface transport in dbcAMP-stimulated Oli-neu cells}

Cells of the Oli-neu line exhibit oligodendroglial progenitor characteristics and can be differentiated to a certain degree by treatment with dbcAMP leading to upregulation of myelin gene expression including synthesis of limited amounts of PLP (mostly the isoform DM20) in a subset of cells (Jung et al., 1995). dbcAMP treatment furthermore regulates trafficking of PLP in Oli-neu cells and mimics the retranslocation of PLP from LE/Lys pools to the plasma membrane observed in oligodendrocytes in response to neuronal signals (Trajkovic et al., 2006). We thus analyzed the functional role of VAMP3 and VAMP7 in cell surface transport of PLP in dbcAMP-treated and nontreated cells.

To interfere with VAMP3-mediated membrane fusion events, we first made use of tetanus neurotoxin (TeNT), a metalloprotease specifically cleaving VAMP1 (not expressed in oligodendroglial cells), VAMP2, and VAMP3. We coexpressed the proteolytically active light chain of TeNT (TeNT-wt) or an inactive mutant variant (TeNT-E234Q) as control (McMahon et al., 1993) together with PLP in Oli-neu cells and analyzed surface transport of PLP. Indeed, VAMP2 and VAMP3 expression was drastically reduced in TeNT-wt compared with TeNT-E234Q expressing cells, whereas VAMP7 expression was unaffected (Fig. $3 A$ ). Costaining of the cells with antibodies against PLP and

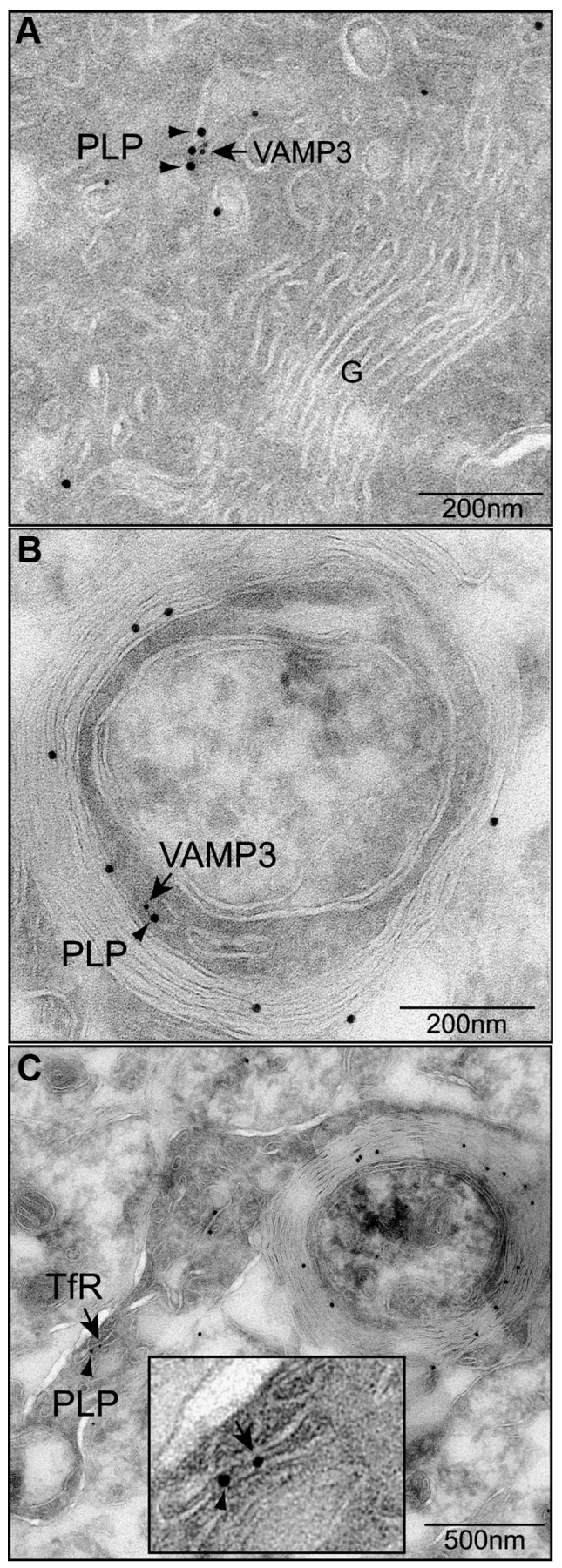

Figure 2. Ultrastructural analysis of VAMP3 and PLP colocalization. $A, B$, Immunolabeling of PLP ( $15 \mathrm{~nm}$ gold, arrowheads) and VAMP3 ( $10 \mathrm{~nm}$ gold; arrows) on ultrathin sections of primary oligodendrocytes $(\boldsymbol{A})$ and myelinating oligodendrocytes $(\boldsymbol{B})$ of P6 spinal cord. VAMP3 and PLP colocalize on tubular membranes within the oligodendroglial cytoplasm. C, Double labeling of PLP (15 nm gold; arrowheads) and TfR (10 nm gold; arrows) in myelinating oligodendrocytes of P6 spinal cord demonstrates PLP localization to membranes of recycling endosomal identity. The inset depicts enlarged area of colocalization.

VAMP3 demonstrated that cells coexpressing PLP and TeNT-wt did not stain for VAMP3, whereas cells coexpressing PLP and TeNT-E234Q were positive for VAMP3 (Fig. 3B; supplemental Fig. S1 A, available at www.jneurosci.org as supplemental material). We further immunostained live cells using $\mathrm{O} 10$ antibodies recognizing an extracellular epitope of PLP to determine surface localization of PLP (Jung et al., 1996). In TeNT-wt-expressing 
cells treated with dbcAMP, we observed a strong reduction of PLP localized to the cell surface compared with TeNT-E234Qexpressing control cells (Fig. 3B). As a measure of PLP surface transport, we determined the relative fluorescence intensities of cell surface PLP and total PLP acquired from confocal image stacks of TeNT-wt- and TeNT-E234Q-expressing cells. In Oli-neu cells devoid of VAMP2 and VAMP3, surface transport of PLP in response to dbcAMP treatment was reduced by $41 \pm 1.8 \%(n=3 ; p=0.002)$. In contrast, surface transport of MOG was not affected by TeNT-mediated cleavage of VAMP2 and VAMP3, indicating that MOG is reaching the plasma membrane by a different pathway independent of VAMP2- and VAMP3-mediated fusion (supplemental Fig. S1B,C, available at www.jneurosci.org as supplemental material).

Since TeNT cleavage does not discriminate between VAMP2 and VAMP3, we used siRNA silencing of VAMP3, resulting in a highly efficient and selective knockdown of VAMP3 while leaving VAMP2 expression unaffected (Fig. 3C,D). In all experiments performed, VAMP3 protein expression levels were reduced by $79 \pm 12.4 \%(n=3, p=$ 0.024 ) compared with cells treated with control siRNA. For reasons of technical simplicity, we performed the siRNA-silencing experiments with Oli-neu cells stably expressing PLP-EGFP (Trajkovic et al., 2006). As described above, surface PLP was determined by $\mathrm{O} 10$ staining and normalized to EGFP fluorescence reflecting the total cellular pool of PLP. In dbcAMP-treated VAMP3 knockdown cells, the relative surface level of PLP was decreased by $57 \pm$ $5.4 \%(n=3 ; p=0.009)$ (Fig. $3 E$ and not depicted). To some extent, this correlated with a reduced tendency of the cells to extend long and branched processes, a phenomenon we did not follow up further in this study. To include a larger population of cells into the analysis, we performed cell ELISAs using the $\mathrm{O} 10$ antibody and determined absolute surface levels of PLP (not depicted). We observed a reduction of surface PLP by $51 \pm 13.1 \%(n=6 ; p=0.014)$, which is in the same range of that detected by fluorescence quantification of individual cells. Notably, knockdown of VAMP3 in Oli-neu cells that were not treated with dbcAMP did not result in decreased surface localization of PLP and indeed showed an opposite trend (supplemental Fig. S2, available at www.jneurosci.org as supplemental material). Untreated Oli-neu cells exhibit a high rate of PLP endocytosis from the plasma membrane, which is strongly reduced in dbcAMP-treated cells (see below) (supplemental Fig. S3, available at www.jneurosci.org as supplemental material). Consequently, the relative level of surface PLP is generally lower in untreated cells. The reduced endocytic turnover of PLP in the plasma membrane of dbcAMP-treated cells may explain why VAMP3-dependent surface transport is only apparent under
B

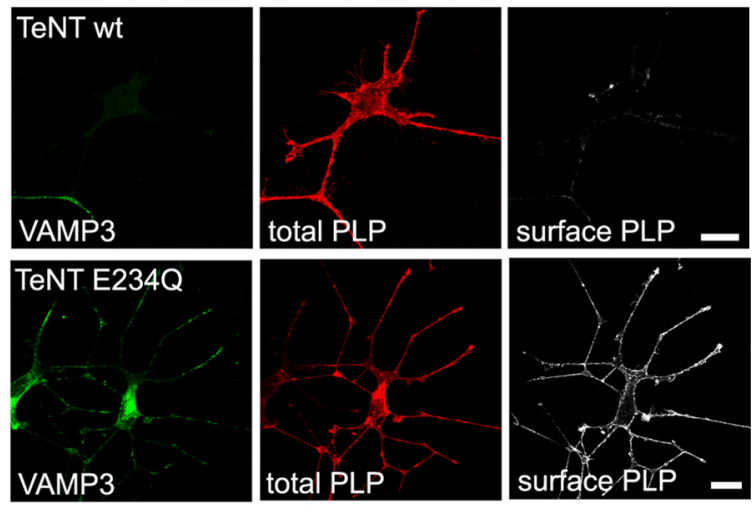

E
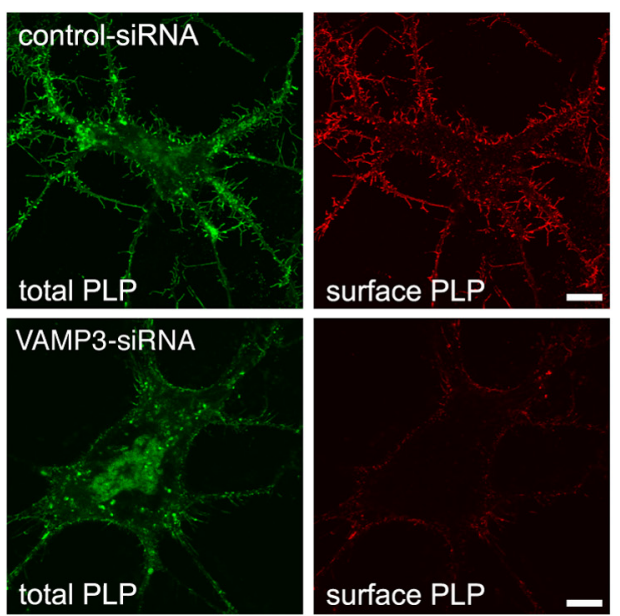

Figure 3. Functional inactivation of VAMP3-mediated fusion. $\boldsymbol{A}, \boldsymbol{B}$, Inactivation of VAMP3 by TeNT-mediated proteolytic cleavage. Oli-neu cells were cotransfected with PLP and TeNT light chain (TeNT-wt) or a mutant inactive form (TeNT-E234Q) ined with antibodies recognizing VAMP3 (green), total PLP (red; aa3 antibody), and surface PLP (white; 010 antibody

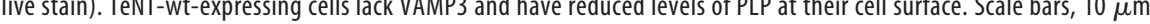
$\boldsymbol{C}-\boldsymbol{E}$, siRNA-mediated silencing of VAMP3 expression in Oli-neu cells stably expressing PLP-EGFP. The cells were transfected , Verficiciency and specificity by Western blot analysis of total cell lysates. VAMP2 expression is no 作 cells (bottom panels) after treatment for $3 \mathrm{~d}$ with dbcAMP showing PLP-EGFP in green (total PLP) and surface PLP in red, as determined by 010 staining.

these conditions. Alternatively, dbcAMP may stimulate VAMP3dependent membrane fusion.

We further tested whether PLP accumulates in LE/Lys or $\mathrm{RE}$ in cells devoid of VAMP3. Colocalization analysis of PLP with TfR and LAMP1 did not show any increase in overlap of PLP with one of these markers in VAMP3-depleted cells. However, we observed a weak but statistically nonsignificant decline of total PLP in VAMP3 siRNA-treated cells possibly indicating increased degradation of accumulating PLP (data not shown).

In summary, TeNT-mediated cleavage of both VAMP2 and VAMP3 as well as siRNA-mediated knockdown of VAMP3 alone reduced transport of PLP to the oligodendroglial plasma membrane to a similar extent. The results suggest that VAMP3 mediates fusion of recycling endosome-derived PLP-containing vesicles (or tubules) with the plasma membrane. This VAMP3dependent transport pathway is prevailing in dbcAMPstimulated cells. 


\section{A}
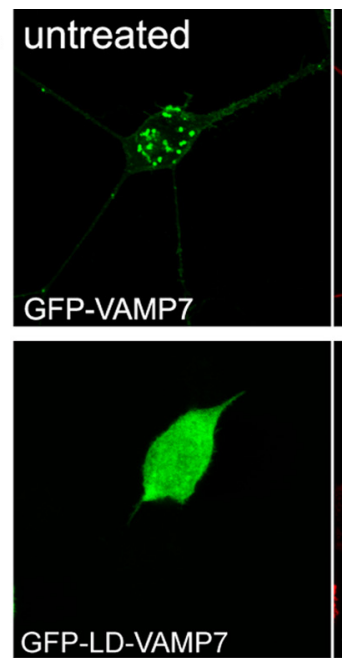

total PLP
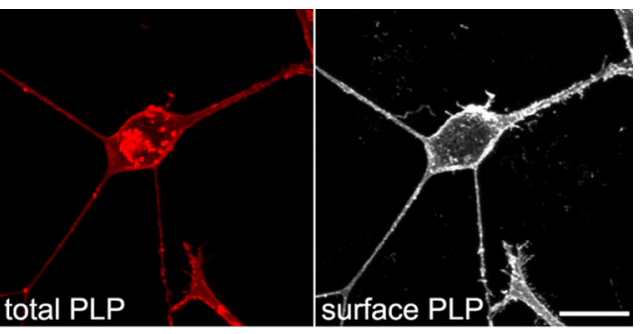

GFP-LD-VAMP7
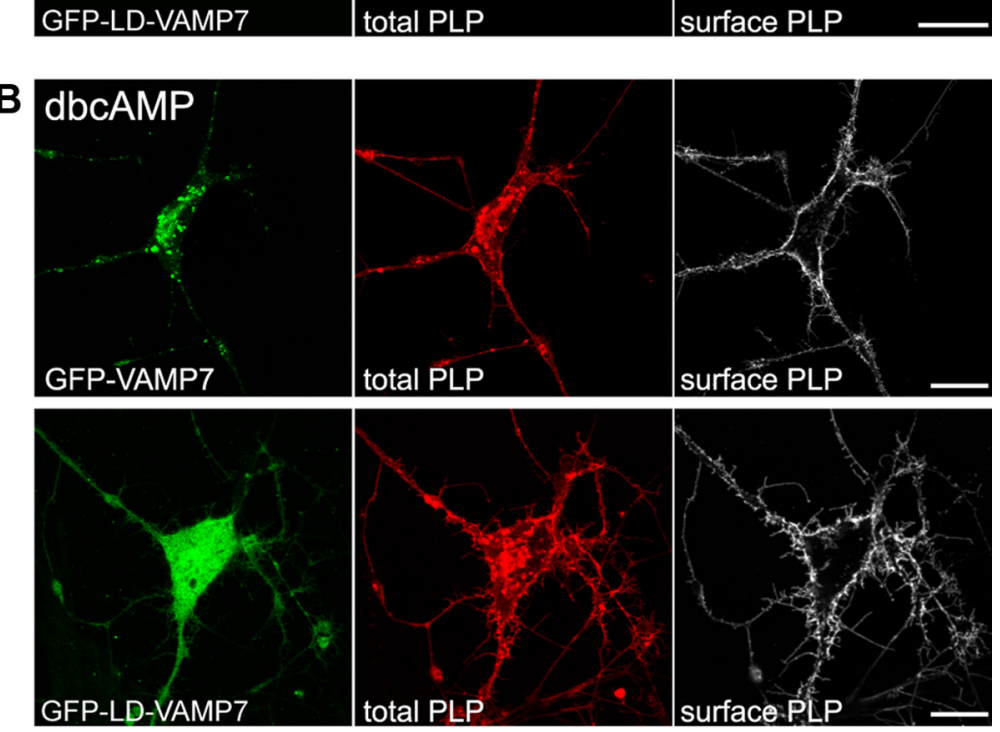

C

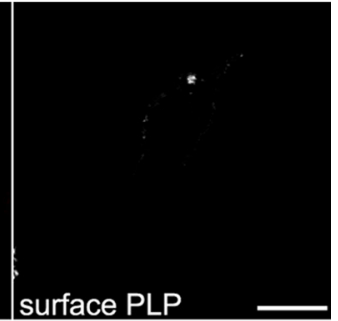

surface: $R$ L

\section{Fluorescence intensity}

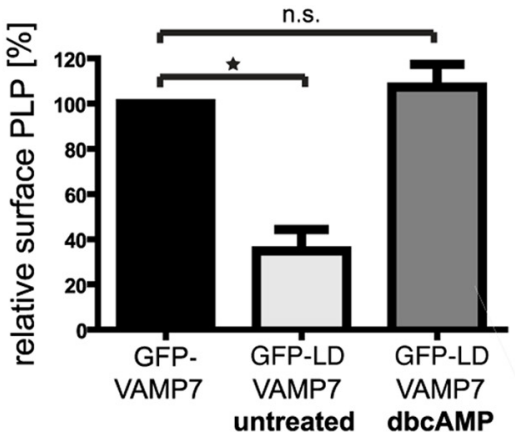

Figure 4. Functional inactivation of VAMP7-mediated fusion by overexpression of the dominant-negative N-terminal Longin domain of VAMP7. Oli-neu cells were transfected to coexpress PLP and EGFP fused to full-length VAMP7 (GFP-VAMP7) or the Longin-domain of VAMP7 (GFP-LD-VAMP7). $A, B$, Immunostaining of cells using antibodies recognizing total PLP (aa3 antibody; red) or surface PLP (010 antibody; white). PLP surface localization is strongly reduced in untreated cells $(\boldsymbol{A})$ but unaffected in $\mathrm{dbcAMP}$-treated cells $(\boldsymbol{B})$. Scale bars, $10 \mu \mathrm{m}$. C, Relative levels of surface PLP calculated by quantification of fluorescence intensity from confocal image stacks of dbcAMP-treated or untreated cells ( 010 staining intensity of surface PLP in relation to aa 3 staining intensity of total PLP). Error bars depict SEM. Paired $t$ test, ${ }^{*} p<0.05 ;$ n.s., not significant; $n=3$.

Functional inactivation of VAMP7 reduces PLP surface transport selectively in nonstimulated Oli-neu cells To address the role of VAMP7 in PLP transport, we overexpressed the N-terminal Longin domain of VAMP7 in Oli-neu cells (GFP-LD-VAMP7), which has been shown to dominant-negatively interfere with VAMP7-mediated fusion reactions by preventing SNARE complex formation (Martinez-Arca et al., 2000; ProuxGillardeaux et al., 2007; Gupton and Gertler, 2010). Plasma membrane transport of PLP in Longin domain-expressing cells was assessed compared with cells expressing full-length VAMP7 (GFPVAMP7), where VAMP7 function should not be corrupted. In Oli-neu cells not treated with dbcAMP, Longin domain overexpression affected cell morphology and the surface expression of PLP was drastically reduced (Fig. 4A). The relative surface localization of PLP, as determined by fluorescence intensity quantification of surface localized versus total PLP of individual cells, was decreased by $65 \pm 9.5 \%$ $(n=3 ; p=0.02)$, whereas the absolute surface localization of PLP, as determined by cell ELISA, was decreased by $39 \pm 6.2 \%$ $(n=5 ; p=0.032)$. The lower impact on PLP transport determined by ELISA may be explained by the inclusion of a small proportion of cells expressing PLP but lacking expression of the VAMP7 Longin domain (cells not harboring both expression vectors). Intriguingly, dbcAMP treatment completely restored the surface transport of PLP in Longin domainexpressing Oli-neu cells (Fig. 4B). In a second approach, we performed siRNA silencing of VAMP7, resulting in a specific knockdown of VAMP7 protein expression levels by $54 \pm 4.5 \%(n=4 ; p=$ 0.001 ) and determined surface expression of PLP by cell ELISA. Again, surface localization of PLP was reduced by $43.5 \pm 12 \%$ $(n=4 ; p=0.036)$ in VAMP7-silenced cells that were not treated with dbcAMP (not depicted).

These results indicate that VAMP7 mediates fusion of LE/Lys-derived PLPcontaining vesicles with the plasma membrane operating preferentially in Oli-neu cells not stimulated with dbcAMP. Thus, at least two trafficking pathways control surface transport of PLP: a VAMP3-dependent pathway from RE and a VAMP7-dependent pathway from LE/Lys. In response to dbcAMP treatment, Oli-neu cells reduce the rate of PLP endocytosis (supplemental Fig. S3, available at www.jneurosci.org as supplemental material) (Trajkovic et al., 2006), preventing trafficking of PLP to VAMP7-decorated LE/Lys. Simultaneously,

VAMP3-dependent surface transport of PLP is operating under these conditions. dbcAMP treatment of Olineu cells thus neutralizes the trafficking defect observed in response to VAMP7 inactivation by enforcing the VAMP3-dependent transport pathway of PLP. 


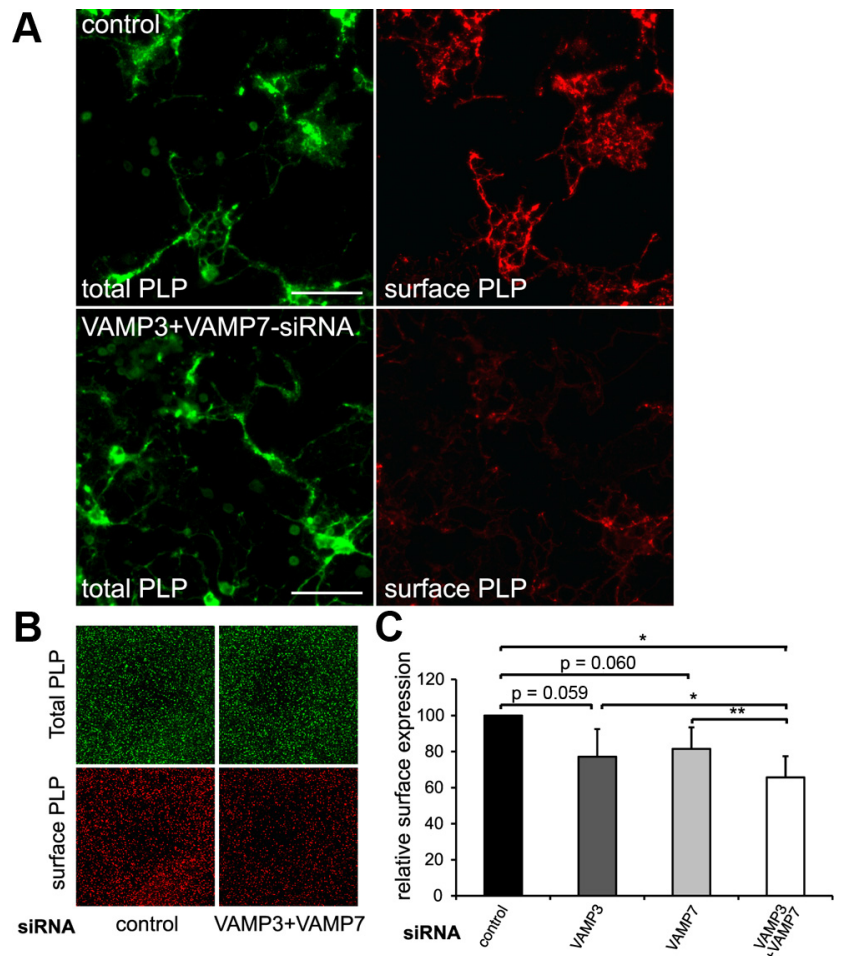

Figure 5. VAMP3 and VAMP7 silencing in primary oligodendrocytes. OPCs were siRNA transfected and differentiated for 3-4d to allow endogenous PLP expression. $\boldsymbol{A}$, Surface-localized and total PLP were determined by immunostaining using 010 and aa 3 antibodies, respectively. Scale bars, $50 \mu \mathrm{m}$. $\boldsymbol{B}$, Odyssey infrared scan depicting total PLP and surface PLP of control siRNA-transfected and VAMP3/VAMP7-cosilenced oligodendrocytes. A detail showing an identical field of the scan is shown. C, Surface PLP normalized to total PLP calculated from 0dyssey scans of siRNA-treated cells ( $n=5$ for single and $n=4$ for double silencing experiments). Error bars depict SEM. Paired $t$ test, ${ }^{*} p<0.05,{ }^{* *} p<0.01$.

\section{Silencing of VAMP3 and VAMP7 in primary oligodendrocytes}

We further performed siRNA silencing of VAMP3 and VAMP7 in primary cultured oligodendrocytes. Isolated oligodendrocyte progenitor cells were siRNA transfected before seeding and relative cell surface expression of PLP was determined after 3-4 d of oligodendroglial differentiation. We used a multiplex in-cell analysis that allows the laser-based detection of total PLP and surface PLP across the whole cell population. Although oligodendrocyte morphology appeared unaffected, we observed a reduction of relative PLP surface levels by $\sim 20 \%$ on VAMP3 or VAMP7 silencing (Fig. 5). This impact on PLP transport in primary oligodendrocytes may appear relatively low; however, it most likely reflects the less efficient siRNA silencing in primary cells compared with Oli-neu cells. Remarkably, only a small number of SNARE complexes are required to allow membrane fusion to occur and suffice to maintain transport with reduced kinetics (Mohrmann et al., 2010).

We further aimed to determine surface transport of PLP under conditions in which both R-SNAREs were functionally inactivated. Silencing of VAMP3 and VAMP7 in primary oligodendrocytes significantly further decreased relative surface levels of PLP by $34.3 \pm 11.7 \%$, indicating that both SNAREs act synergistically. This is consistent with the concept that VAMP3 and VAMP7 act in distinct PLP transport pathways. In Oli-neu cells, cosilencing of both R-SNAREs resulted in transport deficiencies similar in dimension to the individual silencing experiments (reduction of relative surface PLP by $41 \pm 8.1 \% ; n=3$ ).
However, the cosilencing efficiency was limited and characterized by sustained SNARE levels of $\sim 40 \%$ of normal (not depicted).

\section{Silencing of VAMP3 and VAMP7 affects formation of} myelin-like membranes in oligodendrocyte-neuron cocultures To study the impact of VAMP3- and VAMP7-dependent transport pathways on myelin formation in vitro, we used neuron-glia cocultures and seeded purified oligodendrocytes on top of cortical neurons. After several days of coculture, oligodendrocytes have established contact and further enwrap the axons, forming segments of glial ensheathment. Within 3 weeks of coculture, these segments elongate and form substantial amounts of myelinlike membranes (MLMs), which share the biochemical and biophysical properties of myelin in vivo (for characterization of the cocultures, see supplemental Fig. 4, available at www.jneurosci. org as supplemental material). Like myelin, MLMs produced in culture are rich in lipids and exhibit low density and thus can be isolated by a density gradient fractionation protocol that was developed to separate compact myelin from noncompact myelin and axon-glia junctions (Matthieu et al., 1973; Rios et al., 2000; Winterstein et al., 2008). MLMs were detected and quantitatively recovered already within the first week of coculture and thus were used as readout for myelin formation in our experimental setup. Before seeding to cortical neurons, primary oligodendrocytes were siRNA transfected. Since knockdown efficiency is limited by the half-life of the siRNA, we analyzed the cultures after $5 \mathrm{~d}$ of coculture by immunostaining and density gradient isolation of MLM fractions (Fig. 6). On silencing of VAMP3 and VAMP7, oligodendrocytes were still able to establish axonal contacts and the cultures exhibited a similar degree of axonal ensheathment (Fig. $6 \mathrm{~A}$ and not depicted). We further determined the association of PLP with MLM in light fractions of density gradients (Fig. $6 B, C)$. Knockdown of VAMP7 significantly reduced the relative amount of PLP present in MLM fractions of density gradients, and simultaneous knockdown of both VAMP3 and VAMP7 further impaired association of PLP with MLMs (reduction to $48.6 \pm 13.9 \%$ ). Concomitantly, the amount of PLP present in higher density fractions increased, consistent with the concept that PLP resides in an immature donor membrane compartment on transport arrest under conditions of VAMP silencing. Notably, individual analysis of DM20 exhibited similar results supporting the notion that both PLP isoforms use the same trafficking machinery.

\section{Syntaxin-3 and $\mathbf{- 4}$ are putative cognate target Q-SNAREs}

To execute membrane fusion, R-SNAREs interact with cognate Q-SNAREs in the target membrane. Putative plasma membrane target SNAREs of VAMP3 and VAMP7 may be the $\mathrm{Q}_{\mathrm{a}}$-SNAREs Stx2, Stx3, Stx4, and the $\mathrm{Q}_{\mathrm{bc}}$-SNARE SNAP23, which all are expressed by oligodendrocytes and localize to the myelin membrane (Feldmann et al., 2009). To identify the $Q_{a}$ receptors of VAMP3 and VAMP7 controlling PLP surface transport, we coexpressed myc-tagged Stx2, Stx3, or Stx4 with PLP in Oli-neu cells. Confocal imaging revealed that all three syntaxins exhibit colocalization with PLP particularly in the growth cones of the cell processes (Fig. 7A). We further coexpressed these syntaxins with GFP-tagged VAMP3 or VAMP7 in Oli-neu cells and performed coimmunoprecipitations to determine the possible interactions between these Q- and R-SNAREs in oligodendroglial cells (Fig. 7B). GFP-VAMP3 was only recovered from immunoprecipitations of Stx4 but not of Stx2 or Stx3, whereas GFP-VAMP7 was selectively recovered from immunoprecipitations of Stx3. 

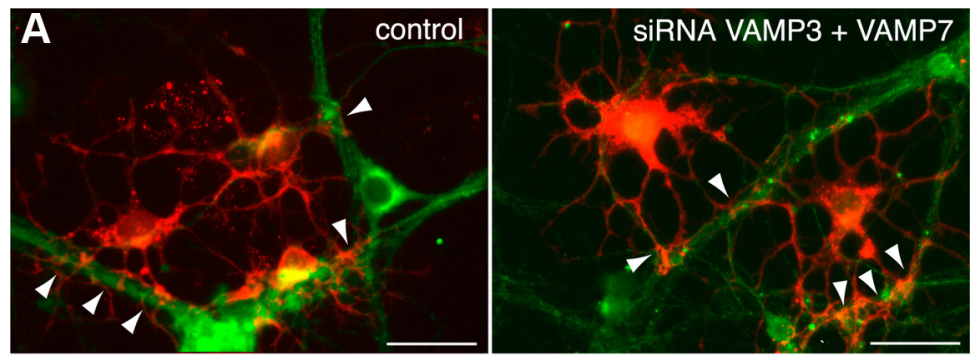

B C
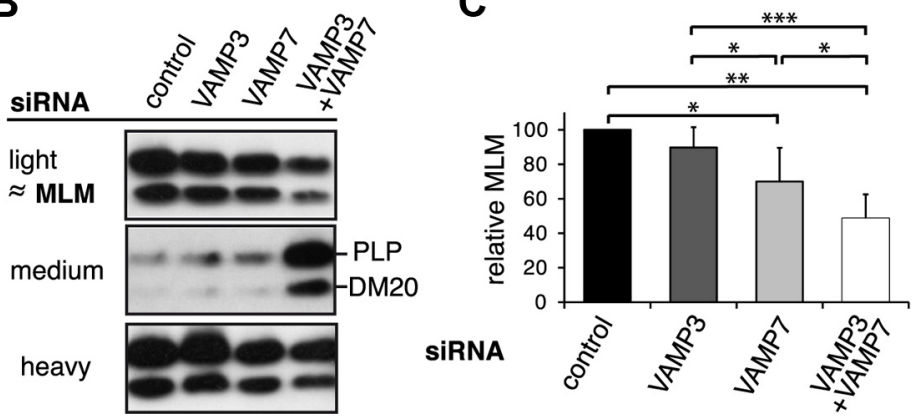

Figure 6. VAMP3 and VAMP7 silencing in neuron-oligodendrocyte cocultures. siRNA-transfected primary oligodendrocytes were seeded on top of primary cortical neurons and cultured for an additional $5 \mathrm{~d}$ to allow initial axon-glia interaction and ensheathment of axons with MLMs. $\boldsymbol{A}$, Immunostaining of cocultures using antibodies recognizing $\beta$ III-tubulin as neurona (green) and PLP as oligodendroglial marker (red). Morphology of oligodendrocytes and extent of axon-glia interaction appeared similar between control cultures and the different siRNA treatment conditions. The arrowheads mark sites of glial axon ensheathment. Scale bars, $25 \mu \mathrm{m} . \boldsymbol{B}, \boldsymbol{C}$, Cocultures were subjected to gradient centrifugation to isolate membrane fractions of high-, medium-, and low-density (light fraction). Light fractions contain MLMs sharing the characteristics of myelin in vivo. $\boldsymbol{B}$, Western blot showing the distribution of PLP between light, medium, and heavy fractions under the different conditions of siRNA treatment. $C$, Densitometric quantification of the relative association of PLP with MLMs $(n=5)$. On RNA silencing of VAMP7 and cosilencing of VAMP3 and VAMP7, association of PLP with the MLM fraction is significantly reduced. Error bars depict SEM. Paired $t$ test, ${ }^{*} p<0.05,{ }^{* *} p<0.01,{ }^{* * *} p<0.001$.

For the interaction to occur, it was essential to coexpress both partners in the same cell. On mixing of individually transfected cells before cell lysis, the interaction between VAMP3 and Stx 4 or VAMP3 and Stx3 was not detectable demonstrating that the interaction had to occur in a living cell and did not result from the solubilization procedure (data not shown) (Feldmann et al., 2009). These results underscore that, even on overexpression in oligodendroglial cells, VAMP3 exhibits specificity toward interaction with Stx4, whereas VAMP7 specifically interacts with Stx3.

VAMP3-deficient mice do not exhibit myelination defects

We further investigated the role of VAMP3-dependent membrane fusion during myelination in vivo and analyzed VAMP3deficient mice (Yang et al., 2001; Borisovska et al., 2005). Animals were killed at the age of $\mathrm{P} 30$, representing a developmental stage immediately after completion of the most active period but ongoing myelination. Western blot analysis of total brain homogenates or purified myelin as well as histochemical analysis involving Gallyas silver impregnation of myelinated tracts and immunohistochemical staining of myelin proteins did not reveal any differences between wild-type, heterozygous, or mutant animals $(n=3)$ (data not shown). This result suggests that VAMP3-dependent transport of PLP is not essential for myelination to proceed. Apparently, the absence of VAMP3 can be compensated in vivo.

\section{AP-3-deficient mocha mice lacking VAMP7 localization to LE/Lys exhibit myelin abnormalities}

To study the role of VAMP7-mediated membrane fusion and lysosomal secretion in myelination in vivo, we made use of the mocha mouse strain, which carries a spontaneous deletion in the Ap3d1 gene, encoding the $\delta 1$ subunit of the adaptor protein $3(\mathrm{AP}-3 \delta)$. It has been shown that $\mathrm{AP}-3 \delta$ interacts with the Longin domain of VAMP7 mediating localization of VAMP7 to LE/Lys. Lack of functional AP-3 results in mislocalization of VAMP7 to early endosomes and hence impaired secretion of lysosome-related organelles (Martinez-Arca et al., 2003; ProuxGillardeaux et al., 2007). mocha mice are characterized by a coat color defect, prolonged bleeding times, and in addition suffer from a series of neurological deficits including seizures (Kantheti et al., 1998; Scheuber et al., 2006; Danglot and Galli, 2007), which may primarily depend on missorting of VAMP7.

We examined myelin formation in brains of P30 mocha mice compared with heterozygous or wild-type littermate control animals. The total brain weight of mocha mice was reduced by $25 \pm 2.3 \%$ $(n=4 ; p=0.002)$. Histochemical staining of myelinated tracts using Gallyas silver impregnation of brain slices appeared slightly weaker in the region of the corpus callosum, striatum, and hippocampus of P30 mocha mice compared with heterozygous littermates (Fig. 8A). Immunohistochemical staining of PLP exhibited reduced signal intensity in particular in the striatum and the hippocampus, where the myelinated fine fibers were almost not detectable (Fig. $8 \mathrm{~B}$ ).

Interestingly, Western blot analysis of total brain homogenates, detecting genuine myelin proteins, such as PLP, CNP, and $\mathrm{MBP}$, revealed significantly lower levels of these proteins in P30 and adult mocha brains, whereas MOG was unaffected (Fig. $8 C, D$ ) (data not shown). We further isolated myelin from mocha and control brains to analyze myelin protein composition. Consistent with the reduced myelin protein levels in total brain homogenates, the yield of total myelin proteins (micrograms of total myelin protein/total brain weight) isolated from mocha brains was reduced by $39 \pm 8.7 \%$ compared with littermate controls $(n=4 ; p=0.047)$, further indicating myelin abnormalities in the mocha CNS. The overall pattern of myelin proteins appeared normal, when equal amounts of total myelin proteins were analyzed by SDS-PAGE followed by silver staining (data not shown). However, if VAMP7-dependent membrane fusion reactions contribute to myelin formation, the absence of VAMP7 from donor compartments in mocha mice should result in reduced levels of VAMP7 and also of the VAMP7-dependent cargo protein PLP in myelin. Western blot analysis indeed confirmed the expected relative reduction of VAMP7 and PLP levels in mocha myelin (Fig. 8E,F). In addition, CNP was strongly underrepresented in mocha myelin. In contrast, the relative abundance of MBP and MOG was unaffected indicating their VAMP7independent transport to myelin.

To investigate whether mocha mice exhibit thinner myelin sheaths, we performed electron microscopy and analyzed myelin ultrastructure in the corpus callosum. However, mocha myelin sheaths appeared with normal compaction and thickness 


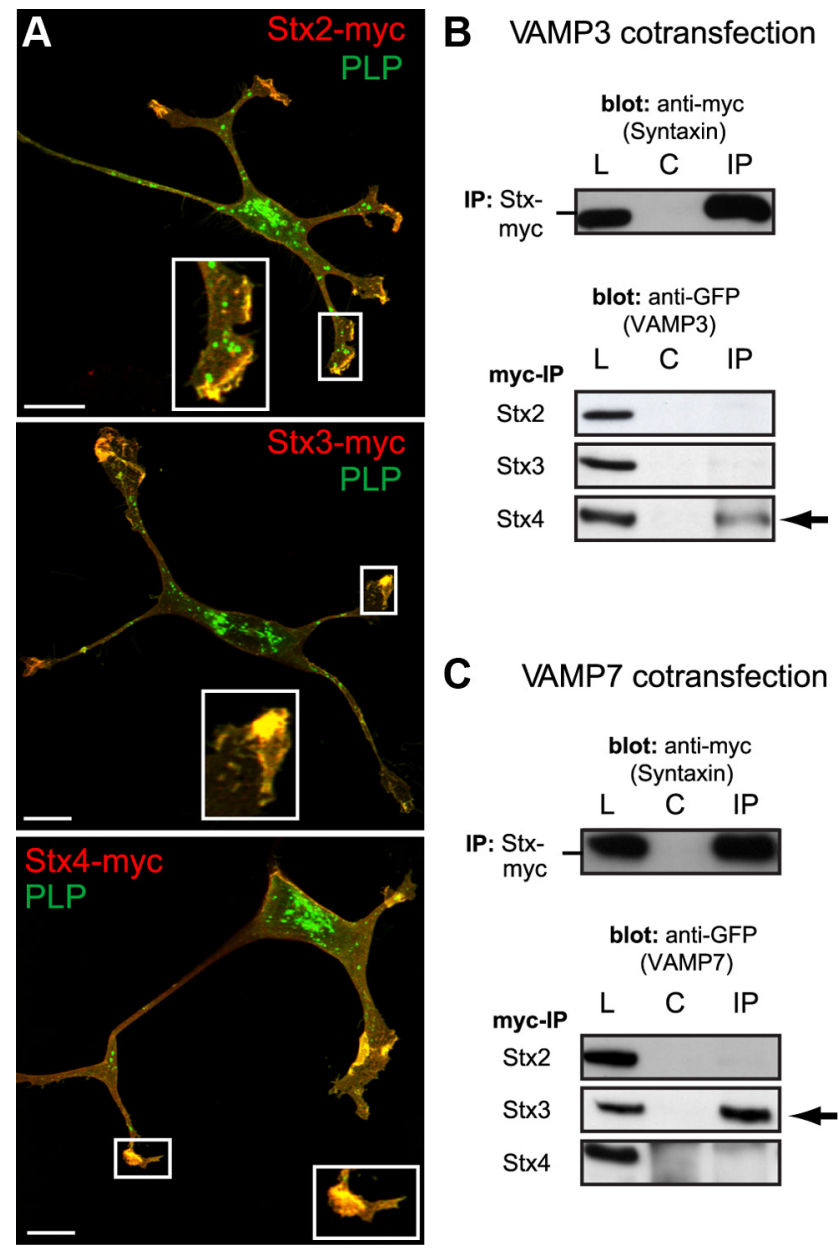

Figure 7. The $Q_{a}$-SNAREs Stx3 and Stx4 function as putative target receptors of VAMP3 and VAMP7 in oligodendroglial cells. $\boldsymbol{A}$, Confocal images of Oli-neu cells cotransfected with PLP and myc-tagged versions of Stx2, Stx3, or Stx4. Immunostainings were performed using aa3 antibodies to detect total PLP (green) and myc antibodies to detect syntaxins (red). Colocalization appears prominently in clusters at terminal ends of the processes (enlarged view in insets). $\boldsymbol{B}, \boldsymbol{C}$, IP of myc-tagged Stx2, Stx3, or Stx4 from lysates of cells cotransfected with GFP-VAMP3 (B) or GFP-VAMP7 (C) using polyclonal myc antibodies. IPs were analyzed by Western blotting using either monoclonal myc antibodies to confirm syntaxin precipitation (top panel) or anti-GFP antibodies detecting coprecipitating VAMP3 or VAMP7 (bottom panels). GFP-VAMP3 is selectively detected in IPs of Stx4-myc, and GFP-VAMP7 is selectively detected in IPs of Stx3myc (arrows). L, Total lysates; C, negative controls showing precipitations without primary antibody included; IP, immunoprecipitation.

(Fig. 8G). The $g$ ratio analysis of myelin thickness in relation to axon diameter did not reveal significant differences between mocha and littermate control mice (Fig. $8 \mathrm{H}$ ). In summary, mocha mice suffering from VAMP7 mislocalization and impaired fusion of lysosome-related organelles exhibit subtle myelin defects primarily characterized by an abnormal protein composition caused by reduced levels of PLP and CNP in the myelin membrane. This observation is consistent with diminished transport of these proteins to the myelin sheath. The results thus strongly suggest that VAMP7 mediates fusion of PLP-containing LE/Lys with the myelin membrane.

\section{Discussion}

Biogenesis of the myelin sheath requires extensive membrane expansion involving targeted fusion of transport vesicles. The aim of this study was to define SNARE proteins regulating key steps of membrane fusion within myelin membrane trafficking pathways. Our results demonstrate that the R-SNAREs VAMP3 and VAMP7 control cell surface delivery of the major myelin protein PLP using two independent transport pathways. VAMP3 appears to mediate plasma membrane fusion of vesicles originating from the RE, whereas VAMP7 controls fusion reactions associated with exocytosis of LE/Lys. The in vivo analysis provides evidence that VAMP7-dependent transport delivers specific components to the myelin membrane without affecting the wrapping process of myelination.

\section{Distinct roles of VAMP3 and VAMP7 in surface delivery of PLP}

Confocal microscopy revealed colocalization of PLP with VAMP3 and VAMP7 in RE and LE/Lys, respectively. Functional ablation of VAMP3 and VAMP7 interfered with PLP transport in oligodendrocytes. LE/Lys localization of PLP and VAMP7 is consistent with the literature (Advani et al., 1999; Krämer et al., 2001; Feldmann et al., 2009). It has been shown that PLP accumulates in LE/Lys on clathrin-independent cholesterol-dependent endocytosis, and furthermore, retranslocation of PLP from LE/Lys storage sites to the plasma membrane is regulated by RhoGTPase inactivation triggered by a soluble neuronal signal (Trajkovic et al., 2006; Kippert et al., 2007). Recycling through LE/Lys facilitates association of PLP with membranes exhibiting specific myelin characteristics (Winterstein et al., 2008). Consistently, we observe that interference with VAMP7 function reduces the inclusion of PLP in myelin-like membranes in neuron-glia cocultures. We thus propose that VAMP7 mediates regulated exocytosis of LE/Lys in response to neuronal signaling, accounting for recycling of PLP and its inclusion into the myelin domain of the oligodendroglial cell surface. The specific role of VAMP7 in regulated exocytosis of LE/Lys is well established in several cell types (Martinez-Arca et al., 2001; Braun et al., 2004; Rao et al., 2004; Arantes and Andrews, 2006; Logan et al., 2006; ProuxGillardeaux et al., 2007; Marcet-Palacios et al., 2008) and appears primarily associated with cellular processes requiring rapid expansion and remodeling of the plasma membrane (Chaineau et al., 2009; Danglot et al., 2010).

Association of VAMP3 with TfR-containing RE membranes is commonly observed (Galli et al., 1994); however, the localization of PLP to RE has not been recognized before. In the steady state, only a small fraction of total cellular PLP is present in RE indicating a transient association of PLP with this compartment. The membranes carrying PLP, TfR, and VAMP3 exhibit the typical ultrastructural appearance of transport intermediates of the secretory pathway (D'Souza-Schorey et al., 1998). On endocytosis from the oligodendroglial plasma membrane, PLP strictly enters the LE/Lys compartment and is never observed in RE (Winterstein et al., 2008). In epithelial cells, it has been demonstrated that a subset of cargos transit through RE intermediates on their biosynthetic route from the Golgi to the cell surface (Ang et al., 2004; Cresawn et al., 2007; Desclozeaux et al., 2008; Farr et al., 2009). Interestingly, the basolateral transport of those cargos traversing RE depends on VAMP3 (Fields et al., 2007). We thus conclude that PLP associates with RE during its biosynthetic transport and that fusion of RE-derived transport intermediates with the oligodendroglial plasma membrane requires VAMP3. Surface delivery via this pathway is not mandatory to all myelin cargos, as the transmembrane myelin protein MOG reaches the cell surface independent of VAMP3.

The surface transport defects observed on ablation of VAMP3 and VAMP7 exhibited distinct sensitivity toward cellular cAMP levels and appeared to act synergistic, suggesting two independent traf- 
A
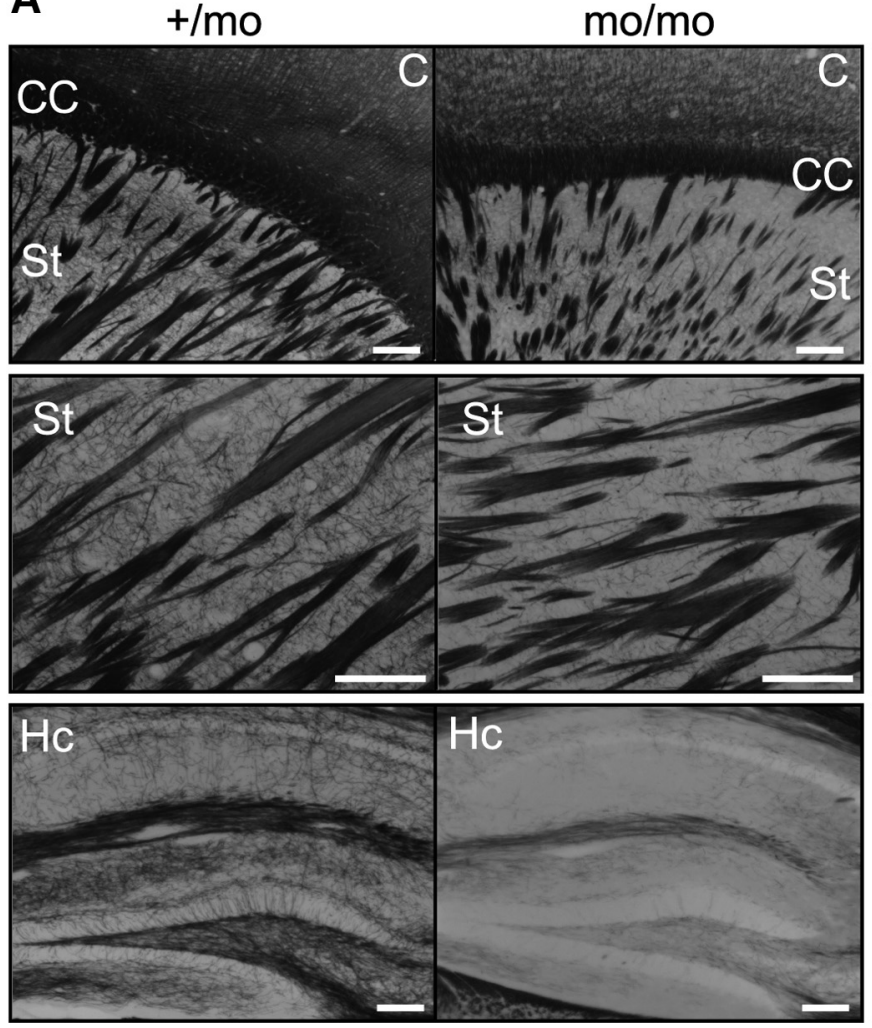

C total brain

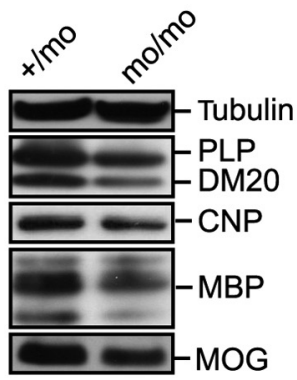

G

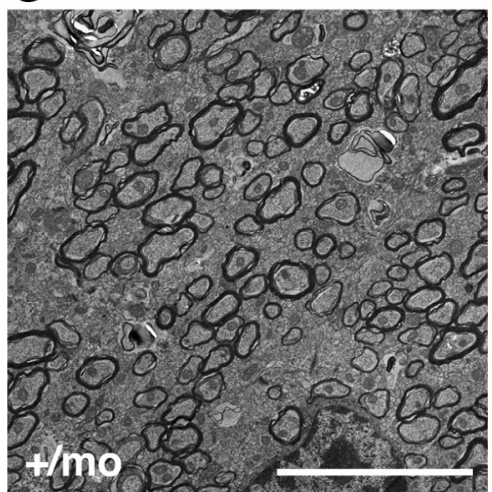

$\mathrm{mo} / \mathrm{mo}$

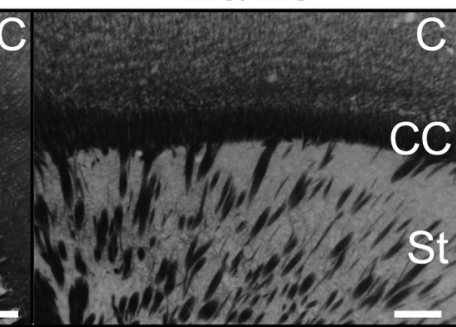

D

Tubulin PLP CNP MBP MOG

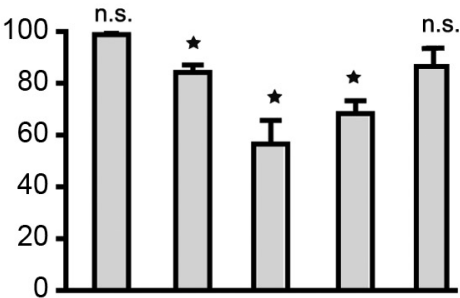

B

$+/ \mathrm{mo}$
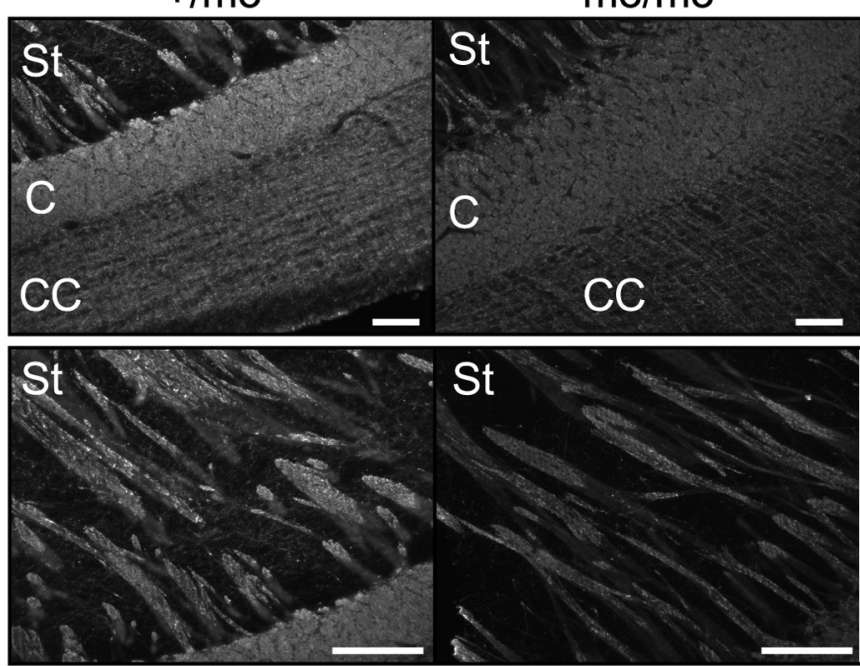

$\mathrm{Hc}$

Hc

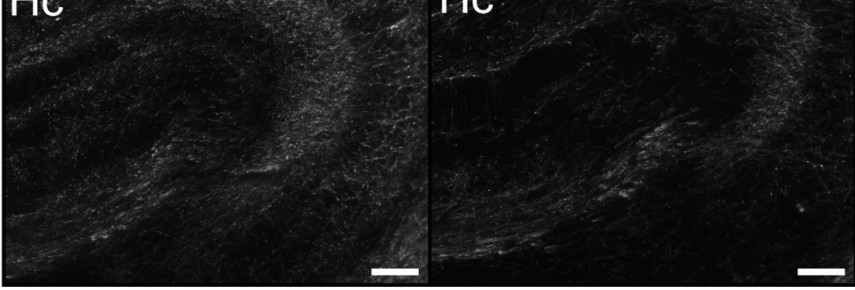

E

$\mathbf{F}$

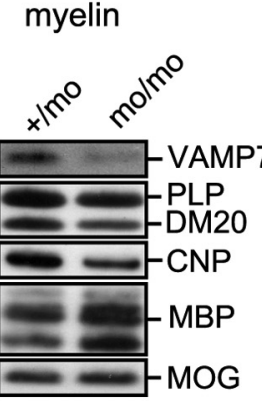

VAMP7 PLP CNP MBP MOG

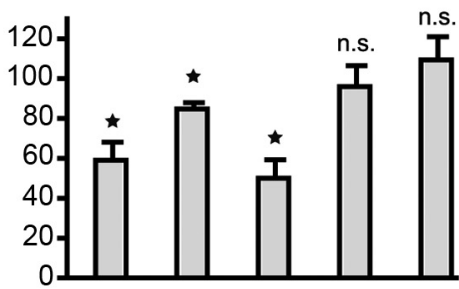

H
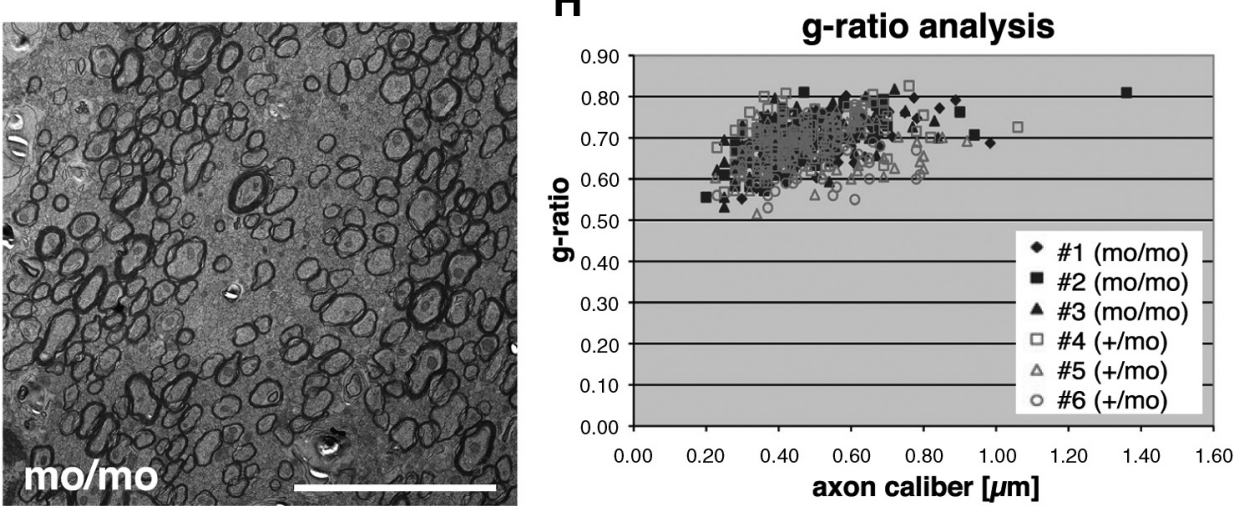

Figure 8. Analysis of myelination in AP-3 8 -deficient mocha mice. $\boldsymbol{A}, \boldsymbol{B}$, Gallyas staining $(\boldsymbol{A})$ and immunohistochemical staining $(\boldsymbol{B})$ of PLP of white matter tracts in brains of P30 mocha (mo/mo) and heterozygous (+/mo) littermate control mice. C, Cortex; $C$ C, corpus callosum; St, striatum; Cb, cerebellum; Hc, hippocampus. Scale bars, $100 \mu \mathrm{m}$. C, D, Western blot analysis of myelin proteins in brain homogenates from P30 mocha and heterozygous littermate control mice normalized to total protein. Tubulin is shown as loading control. $\boldsymbol{D}$, Densitometric quantification of Western blots depicting relative levels of myelin proteins in mocha brains normalized to heterozygous littermates ( $n=3$; SEM; paired $t$ test, $\left.{ }^{*} p<0.05\right)$. $\boldsymbol{E}$, $\boldsymbol{F}$, Western blot analysis of isolated myelin from P30 mocha and heterozygous littermate control mice normalized to total myelin protein. $F$, Densitometric quantification of Western blots showing relative levels of proteins in mocha myelin normalized to heterozygous littermates $\left(n=3\right.$; SEM; paired $t$ test, $\left.{ }^{*} p<0.05\right)$. G, Electron micrographs taken from the region of the corpus callosum of mocha mice (mo/mo) and heterozygous littermates $(+/ \mathrm{mo})$. Scale bar, $5 \mu \mathrm{m} . \boldsymbol{H}, g$ ratio analysis of myelin sheath thickness in relation to axon diameter in mocha mice. 
ficking pathways (illustrated in Fig. 9). Accordingly, PLP initially travels from the Golgi to RE before arriving at the plasma membrane in a VAMP3-dependent manner. On endocytosis, PLP is stored in LE/Lys and delivered back to the myelin domain of the plasma membrane by VAMP7dependent exocytosis. The pathways may also be classified as TeNT-sensitive and TeNT-resistant pathways, respectively (Proux-Gillardeaux et al., 2005). High intracellular cAMP levels stimulate exocytosis and reduce the rate of endocytosis, thus reinforcing VAMP3-dependent surface transport and furthermore conquering the inhibition of VAMP7-dependent transport. Possibly, additional redundant pathways controlled by other R-SNAREs such as VAMP2 and VAMP4 account for surface transport in oligodendrocytes. It has been shown that ablation of myosin-Va affects VAMP2 localization and functional inactivation of VAMP2 by application of blocking antibodies or treatment with TeNT (certainly also inactivating VAMP3) affects oligodendroglial process growth (Sloane and Vartanian, 2007).

\section{Target Q-SNAREs of VAMP3 and VAMP7}

To accomplish membrane fusion, vesicular R-SNAREs specifically assemble with target membrane-associated Q-SNAREs. SNARE complex formation is regulated by cell type-specific accessory proteins, hence pairing between R- and Q-SNAREs has to be assessed for each cell type (Jahn and Scheller, 2006). We show that, in oligodendroglial cells, VAMP3 and VAMP7 selectively interact with Stx4 and Stx3, respectively. Interestingly, equivalent SNARE combinations control the specific targeting of cargos to apical and basolateral membrane domains of epithelial cells: VAMP7/Stx3 mediates apical membrane fusion and VAMP3/Stx4 controls transport of basolateral cargos via the RE intermediate pathway (Galli et al., 1998; Lafont et al., 1999; Fields et al., 2007; Pocard et al., 2007). Moreover, apical targeting of Stx3 is essential for the development of epithelial cell polarity (Sharma et al., 2006). In oligodendrocytes, Stx3 and Stx4 interact with SNAP23, and all three are upregulated during differentiation, as is VAMP3. Moreover, Stx3 and Stx4 accumulate in myelin during development, as expected for Q-SNAREs actively participating in myelin membrane fusion events (Feldmann et al., 2009). We thus propose that Stx 4 acts as target Q-SNARE in VAMP3-dependent transport of PLP from RE to the oligodendroglial plasma membrane, whereas Stx3 operates in VAMP7dependent transport from LE to the myelin domain. Interestingly, Stx4 is phosphorylated by protein kinase A (Foster et al., 1998), which may also explain the regulatory role of cAMP in VAMP3dependent exocytosis of PLP. The Q-SNARE SNAP29 has also been proposed to regulate surface transport of PLP, most likely by interaction with the GTPase Rab-3A (Schardt et al., 2009). SNAP29, however, pairs with Stx6 and VAMP4 in oligodendroglial cells (Feldmann et al., 2009) and thus is unlikely to be involved in VAMP3- or VAMP7-dependent transport.

\section{Role of VAMP3 and VAMP7 in myelination}

Analysis of myelination in VAMP3-deficient and mocha mice, suffering from a defect in lysosomal secretion because of VAMP7 missorting, demonstrates that both VAMP3 and VAMP7 are not essential for myelin formation per se. Intriguingly, mocha mice exhibit reduced levels of PLP and CNP in myelin of normal ultrastructure, indicating a role of VAMP7 and lysosomal secretion in integrating these proteins into the myelin domain. Since mocha mice lack expression of the adaptor protein AP3 $\delta$ (Kantheti et al., 1998), we presently cannot exclude that absence of AP3 $\delta$ influences PLP and CNP trafficking independent of VAMP7. However, the absence of VAMP7 from mocha myelin confirms VAMP7 missorting in oligodendrocytes and supports the assumption of defective VAMP7-dependent lysosomal secretion. Our data thus suggest that the VAMP7-dependent pathway, but not the VAMP3-dependent pathway, contributes to myelin morphogenesis in vivo. It will be interesting to determine the effect of combined ablation of VAMP3 and VAMP7 on myelination. Taking into account our in vitro data, we, however, assume that redundant transport pathways compensate lack of VAMP3 and VAMP7 function to achieve delivery of PLP. The establishment of multiple surface trafficking pathways involving endosomal compartments and redundancy among SNAREs is common to cells with sophisticated membrane compartment organization such as epithelial cells, adipocytes, and neurons (Borisovska et al., 2005; Farr et al., 2009; Zhao et al., 2009), allowing the cells to maintain their major functions within the organ despite the loss of individual components.

Why do oligodendrocytes use endosomal compartments for trafficking of myelin components? There is accumulating evidence that oligodendrocytes, which simultaneously assemble myelin sheaths at multiple subcellular sites, use endosomes as local internal membrane sorting and storage compartments, from which membrane is rapidly recruited to the sites of membrane growth controlled by neuronal signaling (Trajkovic et al., 2006; Kippert et al., 2007; Winterstein et al., 2008). Our study demonstrates that VAMP3 and VAMP7 mediate surface delivery from RE and LE/Lys, respectively. The important role of LE/Lys function in myelination is illustrated by those cases of Pelizaeus Merzbacher disease, in which overexpression of PLP links functional perturbation of LE/Lys to severe dysmyelination (Simons et al., 2002). In addition, increasing interest should be drawn 
toward potential myelin defects in patients suffering from diseases characterized by defects in lysosomal secretion such as Griscelli syndrome (Sloane and Vartanian, 2007).

\section{References}

Advani RJ, Yang B, Prekeris R, Lee KC, Klumperman J, Scheller RH (1999) VAMP-7 mediates vesicular transport from endosomes to lysosomes. J Cell Biol 146:765-776.

Ang AL, Taguchi T, Francis S, Fölsch H, Murrells LJ, Pypaert M, Warren G, Mellman I (2004) Recycling endosomes can serve as intermediates during transport from the Golgi to the plasma membrane of MDCK cells. J Cell Biol 167:531-543.

Arantes RM, Andrews NW (2006) A role for synaptotagmin VII-regulated exocytosis of lysosomes in neurite outgrowth from primary sympathetic neurons. J Neurosci 26:4630-4637.

Baron W, Hoekstra D (2010) On the biogenesis of myelin membranes: sorting, trafficking and cell polarity. FEBS Lett 584:1760-1770.

Bock JB, Matern HT, Peden AA, Scheller RH (2001) A genomic perspective on membrane compartment organization. Nature 409:839-841.

Borisovska M, Zhao Y, Tsytsyura Y, Glyvuk N, Takamori S, Matti U, Rettig J, Südhof T, Bruns D (2005) v-SNAREs control exocytosis of vesicles from priming to fusion. EMBO J 24:2114-2126.

Braun V, Fraisier V, Raposo G, Hurbain I, Sibarita JB, Chavrier P, Galli T, Niedergang F (2004) TI-VAMP/VAMP7 is required for optimal phagocytosis of opsonised particles in macrophages. EMBO J 23:4166-4176.

Chaineau M, Danglot L, Galli T (2009) Multiple roles of the vesicularSNARE TI-VAMP in post-Golgi and endosomal trafficking. FEBS Lett 583:3817-3826.

Cresawn KO, Potter BA, Oztan A, Guerriero CJ, Ihrke G, Goldenring JR, Apodaca G, Weisz OA (2007) Differential involvement of endocytic compartments in the biosynthetic traffic of apical proteins. EMBO J 26:3737-3748.

Danglot L, Galli T (2007) What is the function of neuronal AP-3? Biol Cell 99:349-361.

Danglot L, Chaineau M, Dahan M, Gendron MC, Boggetto N, Perez F, Galli T (2010) Role of TI-VAMP and CD82 in EGFR cell-surface dynamics and signaling. J Cell Sci 123:723-735.

Desclozeaux M, Venturato J, Wylie FG, Kay JG, Joseph SR, Le HT, Stow JL (2008) Active Rabl1 and functional recycling endosome are required for E-cadherin trafficking and lumen formation during epithelial morphogenesis. Am J Physiol Cell Physiol 295:C545-C556.

D'Souza-Schorey C, van Donselaar E, Hsu VW, Yang C, Stahl PD, Peters PJ (1998) ARF6 targets recycling vesicles to the plasma membrane: insights from an ultrastructural investigation. J Cell Biol 140:603-616.

Farr GA, Hull M, Mellman I, Caplan MJ (2009) Membrane proteins follow multiple pathways to the basolateral cell surface in polarized epithelial cells. J Cell Biol 186:269-282.

Fasshauer D, Sutton RB, Brunger AT, Jahn R (1998) Conserved structural features of the synaptic fusion complex: SNARE proteins reclassified as Qand R-SNAREs. Proc Natl Acad Sci U S A 95:15781-15786.

Feldmann A, Winterstein C, White R, Trotter J, Krämer-Albers EM (2009) Comprehensive analysis of expression, subcellular localization, and cognate pairing of SNARE proteins in oligodendrocytes. J Neurosci Res 87:1760-1772.

Fields IC, Shteyn E, Pypaert M, Proux-Gillardeaux V, Kang RS, Galli T, Fölsch $\mathrm{H}$ (2007) v-SNARE cellubrevin is required for basolateral sorting of AP-1B-dependent cargo in polarized epithelial cells. J Cell Biol 177:477-488.

Foster LJ, Yeung B, Mohtashami M, Ross K, Trimble WS, Klip A (1998) Binary interactions of the SNARE proteins syntaxin-4, SNAP23, and VAMP-2 and their regulation by phosphorylation. Biochemistry 37:11089-11096.

Galli T, Chilcote T, Mundigl O, Binz T, Niemann H, De Camilli P (1994) Tetanus toxin-mediated cleavage of cellubrevin impairs exocytosis of transferrin receptor-containing vesicles in $\mathrm{CHO}$ cells. J Cell Biol 125:1015-1024.

Galli T, Zahraoui A, Vaidyanathan VV, Raposo G, Tian JM, Karin M, Niemann H, Louvard D (1998) A novel tetanus neurotoxin-insensitive vesicle-associated membrane protein in SNARE complexes of the apical plasma membrane of epithelial cells. Mol Biol Cell 9:1437-1448.

Gallyas F (1979) Silver staining of myelin by means of physical development. Neurol Res 1:203-209.
Gupton SL, Gertler FB (2010) Integrin signaling switches the cytoskeletal and exocytic machinery that drives neuritogenesis. Dev Cell 18:725-736.

Hoogenraad CC, Popa I, Futai K, Martinez-Sanchez E, Wulf PS, van Vlijmen T, Dortland BR, Oorschot V, Govers R, Monti M, Heck AJ, Sheng M, Klumperman J, Rehmann H, Jaarsma D, Kapitein LC, van der Sluijs P (2010) Neuron specific Rab4 effector GRASP-1 coordinates membrane specialization and maturation of recycling endosomes. PLoS Biol 8:e1000283.

Jahn R, Scheller RH (2006) SNAREs-engines for membrane fusion. Nat Rev Mol Cell Biol 7:631-643.

Jung M, Krämer E, Grzenkowski M, Tang K, Blakemore W, Aguzzi A, Khazaie K, Chlichlia K, von Blankenfeld G, Kettenmann H (1995) Lines of murine oligodendroglial precursor cells immortalized by an activated neu tyrosine kinase show distinct degrees of interaction with axons in vitro and in vivo. Eur J Neurosci 7:1245-1265.

Jung M, Sommer I, Schachner M, Nave KA (1996) Monoclonal antibody O10 defines a conformationally sensitive cell-surface epitope of proteolipid protein (PLP): evidence that PLP misfolding underlies dysmyelination in mutant mice. J Neurosci 16:7920-7929.

Kantheti P, Qiao X, Diaz ME, Peden AA, Meyer GE, Carskadon SL, Kapfhamer D, Sufalko D, Robinson MS, Noebels JL, Burmeister M (1998) Mutation in AP-3 delta in the mocha mouse links endosomal transport to storage deficiency in platelets, melanosomes, and synaptic vesicles. Neuron 21:111-122.

Karlsson U, Schultz RL (1965) Fixation of the central nervous system from electron microscopy by aldehyde perfusion. I. Preservation with aldehyde perfusates versus direct perfusion with osmium tetroxide with special reference to membranes and the extracellular space. J Ultrastruct Res 12:160-186.

Kippert A, Trajkovic K, Rajendran L, Ries J, Simons M (2007) Rho regulates membrane transport in the endocytic pathway to control plasma membrane specialization in oligodendroglial cells. J Neurosci 27:3560-3570.

Krämer EM, Koch T, Niehaus A, Trotter J (1997) Oligodendrocytes direct glycosyl phosphatidylinositol-anchored proteins to the myelin sheath in glycosphingolipid-rich complexes. J Biol Chem 272:8937-8945.

Krämer EM, Schardt A, Nave KA (2001) Membrane traffic in myelinating oligodendrocytes. Microsc Res Tech 52:656-671.

Krämer-Albers EM, Gehrig-Burger K, Thiele C, Trotter J, Nave KA (2006) Perturbed interactions of mutant proteolipid protein/DM20 with cholesterol and lipid rafts in oligodendroglia: implications for dysmyelination in spastic paraplegia. J Neurosci 26:11743-11752.

Lafont F, Verkade P, Galli T, Wimmer C, Louvard D, Simons K (1999) Raft association of SNAP receptors acting in apical trafficking in Madin-Darby canine kidney cells. Proc Natl Acad Sci U S A 96:3734-3738.

Li F, Pincet F, Perez E, Eng WS, Melia TJ, Rothman JE, Tareste D (2007) Energetics and dynamics of SNAREpin folding across lipid bilayers. Nat Struct Mol Biol 14:890-896.

Liou W, Geuze HJ, Slot JW (1996) Improving structural integrity of cryosections for immunogold labeling. Histochem Cell Biol 106:41-58.

Logan MR, Lacy P, Odemuyiwa SO, Steward M, Davoine F, Kita H, Moqbel R (2006) A critical role for vesicle-associated membrane protein-7 in exocytosis from human eosinophils and neutrophils. Allergy 61:777-784.

Low SH, Vasanji A, Nanduri J, He M, Sharma N, Koo M, Drazba J, Weimbs T (2006) Syntaxins 3 and 4 are concentrated in separate clusters on the plasma membrane before the establishment of cell polarity. Mol Biol Cell 17:977-989.

Marcet-Palacios M, Odemuyiwa SO, Coughlin JJ, Garofoli D, Ewen C, Davidson CE, Ghaffari M, Kane KP, Lacy P, Logan MR, Befus AD, Bleackley RC, Moqbel R (2008) Vesicle-associated membrane protein 7 (VAMP-7) is essential for target cell killing in a natural killer cell line. Biochem Biophys Res Commun 366:617-623.

Martinez-Arca S, Alberts P, Zahraoui A, Louvard D, Galli T (2000) Role of tetanus neurotoxin insensitive vesicle-associated membrane protein (TI-VAMP) in vesicular transport mediating neurite outgrowth. J Cell Biol 149:889-900.

Martinez-Arca S, Coco S, Mainguy G, Schenk U, Alberts P, Bouillé P, Mezzina M, Prochiantz A, Matteoli M, Louvard D, Galli T (2001) A common exocytotic mechanism mediates axonal and dendritic outgrowth. J Neurosci 21:3830-3838.

Martinez-Arca S, Rudge R, Vacca M, Raposo G, Camonis J, ProuxGillardeaux V, Daviet L, Formstecher E, Hamburger A, Filippini F, D’Esposito M, Galli T (2003) A dual mechanism controlling the local- 
ization and function of exocytic v-SNAREs. Proc Natl Acad Sci U S A 100:9011-9016.

Matthieu JM, Quarles RH, Brady RO, Webster Hde F (1973) Variation of proteins, enzyme markers and gangliosides in myelin subfractions. Biochim Biophys Acta 329:305-317.

Maxfield FR, McGraw TE (2004) Endocytic recycling. Nat Rev Mol Cell Biol 5:121-132.

McMahon HT, Ushkaryov YA, Edelmann L, Link E, Binz T, Niemann H, Jahn R, Südhof TC (1993) Cellubrevin is a ubiquitous tetanus-toxin substrate homologous to a putative synaptic vesicle fusion protein. Nature 364:346-349.

McNew JA, Parlati F, Fukuda R, Johnston RJ, Paz K, Paumet F, Söllner TH, Rothman JE (2000) Compartmental specificity of cellular membrane fusion encoded in SNARE proteins. Nature 407:153-159.

Mohrmann R, de Wit H, Verhage M, Neher E, Sørensen JB (2010) Fast vesicle fusion in living cells requires at least three SNARE complexes. Science 330:502-505.

Norton WT, Poduslo SE (1973) Myelination in rat brain: method of myelin isolation. J Neurochem 21:749-757.

Pocard T, Le Bivic A, Galli T, Zurzolo C (2007) Distinct v-SNAREs regulate direct and indirect apical delivery in polarized epithelial cells. J Cell Sci 120:3309-3320

Proux-Gillardeaux V, Rudge R, Galli T (2005) The tetanus neurotoxinsensitive and insensitive routes to and from the plasma membrane: fast and slow pathways? Traffic 6:366-373.

Proux-Gillardeaux V, Raposo G, Irinopoulou T, Galli T (2007) Expression of the Longin domain of TI-VAMP impairs lysosomal secretion and epithelial cell migration. Biol Cell 99:261-271.

Rao SK, Huynh C, Proux-Gillardeaux V, Galli T, Andrews NW (2004) Identification of SNAREs involved in synaptotagmin VII-regulated lysosomal exocytosis. J Biol Chem 279:20471-20479.

Rios JC, Melendez-Vasquez CV, Einheber S, Lustig M, Grumet M, Hemperly J, Peles E, Salzer JL (2000) Contactin-associated protein (Caspr) and contactin form a complex that is targeted to the paranodal junctions during myelination. J Neurosci 20:8354-8364.

Roth J, Bendayan M, Orci L (1978) Ultrastructural localization of intracellular antigens by the use of protein A-gold complex. J Histochem Cytochem 26:1074-1081.

Scales SJ, Chen YA, Yoo BY, Patel SM, Doung YC, Scheller RH (2000) SNAREs contribute to the specificity of membrane fusion. Neuron 26:457-464.

Schardt A, Brinkmann BG, Mitkovski M, Sereda MW, Werner HB, Nave KA (2009) The SNARE protein SNAP-29 interacts with the GTPase Rab3A: implications for membrane trafficking in myelinating glia. J Neurosci Res 87:3465-3479.
Scheuber A, Rudge R, Danglot L, Raposo G, Binz T, Poncer JC, Galli T (2006) Loss of AP-3 function affects spontaneous and evoked release at hippocampal mossy fiber synapses. Proc Natl Acad Sci U S A 103:16562-16567.

Sharma N, Low SH, Misra S, Pallavi B, Weimbs T (2006) Apical targeting of syntaxin 3 is essential for epithelial cell polarity. J Cell Biol 173:937-948.

Sherman DL, Brophy PJ (2005) Mechanisms of axon ensheathment and myelin growth. Nat Rev Neurosci 6:683-690.

Simons M, Trajkovic K (2006) Neuron-glia communication in the control of oligodendrocyte function and myelin biogenesis. J Cell Sci 119:4381-4389.

Simons M, Trotter J (2007) Wrapping it up: the cell biology of myelination. Curr Opin Neurobiol 17:533-540.

Simons M, Krämer EM, Macchi P, Rathke-Hartlieb S, Trotter J, Nave KA, Schulz JB (2002) Overexpression of the myelin proteolipid protein leads to accumulation of cholesterol and proteolipid protein in endosomes/ lysosomes: implications for Pelizaeus-Merzbacher disease. J Cell Biol 157:327-336.

Sloane JA, Vartanian TK (2007) Myosin Va controls oligodendrocyte morphogenesis and myelination. J Neurosci 27:11366-11375.

Slot JW, Geuze HJ (1985) A new method of preparing gold probes for multiple-labeling cytochemistry. Eur J Cell Biol 38:87-93.

Südhof TC, Rothman JE (2009) Membrane fusion: grappling with SNARE and SM proteins. Science 323:474-477.

Trajkovic K, Dhaunchak AS, Goncalves JT, Wenzel D, Schneider A, Bunt G, Nave KA, Simons M (2006) Neuron to glia signaling triggers myelin membrane exocytosis from endosomal storage sites. J Cell Biol 172:937-948.

Werner HB, Kuhlmann K, Shen S, Uecker M, Schardt A, Dimova K, Orfaniotou F, Dhaunchak A, Brinkmann BG, Möbius W, Guarente L, Casaccia-Bonnefil P, Jahn O, Nave KA (2007) Proteolipid protein is required for transport of sirtuin 2 into CNS myelin. J Neurosci 27:7717-7730.

White R, Gonsior C, Krämer-Albers EM, Stohr N, Huttelmaier S, Trotter J (2008) Activation of oligodendroglial Fyn kinase enhances translation of mRNAs transported in hnRNP A2-dependent RNA granules. J Cell Biol 181:579-586.

Winterstein C, Trotter J, Krämer-Albers EM (2008) Distinct endocytic recycling of myelin proteins promotes oligodendroglial membrane remodeling. J Cell Sci 121:834-842.

Yang C, Mora S, Ryder JW, Coker KJ, Hansen P, Allen LA, Pessin JE (2001) VAMP3 null mice display normal constitutive, insulin- and exerciseregulated vesicle trafficking. Mol Cell Biol 21:1573-1580.

Zhao P, Yang L, Lopez JA, Fan J, Burchfield JG, Bai L, Hong W, Xu T, James DE (2009) Variations in the requirement for v-SNAREs in GLUT4 trafficking in adipocytes. J Cell Sci 122:3472-3480. 